\title{
8 Opportunities for Improving Crop Water Productivity through Genetic Enhancement of Dryland Crops
}

\author{
C.L.L. Gowda, ${ }^{1 *}$ R. Serraj, ${ }^{5 * *}$ G. Srinivasan, ${ }^{2}$ Y.S. Chauhan, ${ }^{4 * * *}$ \\ B.V.S. Reddy, ${ }^{1 * * * *}$ K.N. Rai ${ }^{1 * * * * *}$ S.N. Nigam, ${ }^{1}$ P.M. Gaur, ${ }^{1}$ \\ L.J. Reddy, ${ }^{1}$ S.L. Dwivedi, ${ }^{1}$ H.D. Upadhyaya, ${ }^{1}$ P.H. Zaidi, ${ }^{3}$ H.K. Rai, ${ }^{3}$ \\ P. Maniselvan, ${ }^{3}$ R. Follkerstma ${ }^{\mathbf{6}}$ and $\mathbf{M}$ Nalini ${ }^{1}$ \\ ${ }^{1}$ International Crops Research Institute for the Semi-Arid Tropics (ICRISAT), \\ Patancheru 502 324, Andhra Pradesh, India; ${ }^{2}$ University of California, Fresno, USA; \\ ${ }^{3}$ CIMMYT's Asia Regional Office, Patancheru 502 324, Andhra Pradesh, India; \\ ${ }^{4}$ Department of Primary Industries and Fisheries, Kingaroy, Queensland, Australia; \\ ${ }^{5}$ Crop \& Environmental Sciences Division, International Rice Research Institute, \\ DAPO Box 7777, Metro Manila, Philippines; ${ }^{6}$ De Ruiter Seeds Inc., \\ Leeuwenhoekweg 522661, CZ, Bergschenhoek, the Netherlands; \\ emails: *c.gowda@cgiar.org; **r.serraj@cgiar.org; ***yash.chauhan@dpi.qld.gov.au; \\ ****b.reddy@cgiar.org; *****k.rai@cgiar.org
}

\section{Introduction}

The importance of water as a major limiting factor in agriculture is increasing due to the unpredictable nature of rainfall and increasing demand for water from domestic and industrial users. In arid and semi-arid regions, which experience absolute or economic shortage of water, there is an urgent need to increase crop water productivity (CWP) at the farm level through genetic enhancement and natural resources management. Natural resources and agronomic management options for higher CWP are driven by several factors related to geographic location, governmental policies, crop preferences, marketing issues and involvement of external inputs, often inconvenient or not attractive to rainfed farmers. Because of scale and resource neutrality, the genetic options are amenable to quicker and wider adoption at farm level for increasing CWP.

Pearl millet (Pennisetum glaucum) and sorghum (Sorghum bicolor) ( $\mathrm{C}_{4}$ crops) and the legumes, groundnut (Arachis hypogaea), chickpea (Cicer arietinum) and pigeonpea (Cajanus cajan) $\left(\mathrm{C}_{3}\right.$ crops), occupy an important place in the cropping systems of seasonally dry arid and semi-arid tropics (SAT). Maize (Zea mays) is an important $\mathrm{C}_{4}$ crop grown in tropical lowlands, tropical and subtropical mid-altitudes, where drought is a major limiting factor for its production and productivity. The $\mathrm{C}_{4}$ crops have higher photosynthetic capacity and are more efficient in nitrogen and water use efficiency (WUE). The legumes fix nitrogen through symbiotic association with Rhizobium bacteria, and compensate to a large extent for their lesser WUE. 
Global warming due to climate change will affect grain yields, more so in tropical than temperate regions. The global average temperatures by the year 2100 could progressively rise by up to $6{ }^{\circ} \mathrm{C}$ under the business-as-usual scenario (http://www.fao.org/docrep/005/y4252e/y4252e 15.htm). Reproductive traits are highly sensitive to high temperature, leading to yield reduction. For example, rice (Oryza sativa) grain yield declined by $10 \%$ for each $1{ }^{\circ} \mathrm{C}$ increase in minimum temperature in the dry season in the Philippines (Peng et al., 2004). A projected 10\% yield reduction in maize will bring losses equal to US $\$ 2$ billion in Africa and Latin America (Jones and Thornton, 2003). The wheat (Tritium aestivum) yields in China are expected to decline by $20 \%$ in 2070 (Hui et al., 2005), while in South Australia by $13.5-32 \%$ under the most likely climate change scenario (Luo et al., 2005).

In this chapter, we discuss the target growing environments and crop sensitivity of pearl millet, sorghum, maize, groundnut, chickpea and pigeonpea to drought; phenotypic screens and natural genetic variations for response to drought; empirical and trait-based breeding methods to enhance drought tolerance; and deployment of emerging biotechnological tools (DNA markers and transgene) to enhance crop adaptation and productivity under droughtstress conditions.

\section{Adaptation in Water-limited Environments}

\section{Crop productivity versus survival mechanisms}

Response of most crops to soil water deficit can be described as a sequence of three successive stages of soil dehydration. Stage I occurs at high soil moisture when water is still freely available from the soil and both stomatal conductance and water vapour loss are maximal. The transpiration rate during this stage is therefore determined by environmental conditions around the leaves. Stage II starts when the rate of water uptake from the soil cannot match the potential transpiration rate. Stomatal conductance declines to keep transpiration rate similar to the uptake of soil water for maintaining the water balance of the plant. Stage III begins when the ability of stomata to adjust to the declining rate of water uptake from the soil has been exhausted, and stomatal conductance is minimal.

Virtually all major processes contributing to crop yield, including leaf photosynthetic rate, leaf expansion and growth, are inhibited late in Stage I or in Stage II of soil drying (Serraj et al., 1999). At the end of Stage II, these growthsupporting processes have reached zero and no further growth occurs in the plants. The focus of Stage III is survival and water conservation, essential for the plant to endure these severe stresses. Plant survival is a critical trait in dryland ecosystems, but for most agricultural situations, Stage III has little relevance to increasing crop yield and water productivity, especially in the case of intermittent drought.

Consequently, the amount of water extracted up to the end of Stage II determines cumulative growth by plants on a particular soil water reservoir. Research on soil water use in crop growth dating $>100$ years has consistently shown an intimate and stable relationship between the plant growth and transpirational water use after correcting for variations in atmospheric humidity (Sinclair et al., 1984). Therefore, options to enhance crop survival do not usually mean an increase in crop yield under drought conditions. Increased crop yields and water productivity require optimization of the physiological processes involved in critical stages (mainly Stage II) of plant response to dehydration.

\section{Target environments and crop sensitivity to drought}

\section{Pearl millet}

Post-flowering (also referred to as terminal) drought stress, either alone or in combination with pre-flowering drought, is common in major pearl millet-growing environments in India. Flowering and grain-filling periods are most sensitive to water stress in pearl millet (Mahalakshmi et al., 1987). Yield reduction in this stage is due to decreased panicle number and grain mass. Usually, the number of grains per panicle is less affected if terminal stress occurs after flowering. The reduction in grain mass observed during terminal drought seems 
to be due to restriction of the assimilate supply rather than due to reduction of the grain storage capacity (Bieler et al., 1993). Under very low water potentials, stomatal closure, and a consequent reduction in photosynthetic activity, has been reported in pearl millet (Henson et al., 1984). However, the supply of assimilates through the mobilization of stored soluble sugars can compensate for the impaired photosynthetic activity (Fussell et al., 1980). The transfer of assimilates from the leaves, with stems serving as a buffer during the grain development, appears to be the main adaptation trait during terminal drought stress in pearl millet (Winkel and Do, 1992). From a study involving normal and extended day length, Mahalakshmi and Bidinger (1985) suggested that photoperiod control of floral initiation can provide an escape mechanism to avoid the coincidence of mid-season water stress with sensitive stages of millet growth.

\section{Sorghum}

Terminal drought is the most limiting factor for sorghum production worldwide. In sub-Saharan Africa drought at both seedling establishment and grain-filling stages is very common. In India, sorghum is grown during both rainy and postrainy seasons. The variable moisture environment during the rainy season can have a severe impact on grain and biomass yield, affecting both pre-flowering and post-flowering stages. Climatic variability and associated genotype $\times$ environment interactions do not permit clear definition of the target environments. Opportunities to make progress in breeding for drought tolerance lie both in understanding the environmental control of crop growth and in developing simplified approaches to modelling (Bidinger et al., 1996).

Drought and/or heat stress at the seedling stage often results in poor emergence, plant death and reduced plant stands. Severe pre-flowering drought stress results in drastic reduction in grain yield. Post-flowering droughtstress tolerance is indicated when plants remain green and fill grain normally. The stay-green trait has been associated with post-flowering drought in sorghum. Genotypes with the staygreen trait are also reported to be resistant to lodging and charcoal rot.

\section{Maize}

Inadequate water availability at critical stages of crop growth and development is the major limiting factor for maize production and productivity in the tropics. Mean rainfall during the crop season appears to be adequate for maize production, but its distribution during the crop cycle has a high coefficient of variability. Normal interseasonal fluctuations in rainfall have been found to be associated closely with variations in average national maize yields across quite large production regions in the tropics (Edmeades et al., 1995), suggesting that water stress is the pervasive cause of yield instability in maizebased cropping systems in the tropics.

Maize is particularly sensitive to water stress in the period 1 week before to 2 weeks after flowering. Stage-sensitivity in maize to drought stress has been studied extensively. Probability of drought in maize-growing environments in the tropics is highest at the start and end of the rainy season, and therefore the crop is prone to facing water deficit at establishment and flowering/grain-filling stages (Banziger et al., 2000a). Monthly rainfall totals in the tropics have a high coefficient of variability, even though mean rainfall appears adequate for maize production. Although the probability of drought stress is lower at silking, its consequences on yield can be highly severe, since the crop is highly susceptible to drought at this stage (Shaw, 1976). Stress from mid- to late grain-filling also reduces grain yields but relatively less in comparison to silking-stage water deficit.

Drought at flowering commonly results in barrenness in genotypes having a longer anthesis-silking interval (ASI). One of the main causes is reduction in the flux of assimilate to the developing ear below some threshold level necessary to sustain grain formation and growth (Westgate and Bassetti, 1990; Schussler and Westgate, 1995). Drought coinciding with this growth period can cause serious yield instability at the farm level. Understanding the nature of the higher grain potential and enhanced yield stability, especially in stress-prone environments, will provide opportunities to improve the selection of stress-tolerant genotypes.

There is an increase in the ASI and a concomitant increase in the number of barren plants in maize under drought (Zaidi et al., 
2003a). A short ASI is considered an indication of the diversion of an increased fraction of the plant's current photosynthesis to the ear, since it is associated with rapid ear growth (Zaidi et al., 2003b). Drought at flowering also affects carbohydrate metabolism of the developing ovule, further reducing sucrose flux to the newly formed seed (Schussler and Westgate, 1995).

\section{Groundnut}

The effect of drought on groundnut is manifested in several ways, affecting both quantity and quality of the crops (Nigam et al., 2002). The three patterns of drought observed in groundnut are early-season, mid-season, and end-of-season drought. A 20- to 25-day moisture stress early in the season (once the crop is established) and its subsequent release by irrigation (or rainfall) has been found to induce heavy and uniform flowering, leading to increased productivity. Groundnut shows increased sensitivity to midseason stress compared with early- and lateseason stresses (Pallas et al., 1979) (Fig. 8.1). Yield progressively decreases as duration of the drought increases and as the mid-season approaches. Water deficit during the late flowering and pod-forming periods is detrimental to groundnut yield (Stansell and Pallas, 1985).
End-of-season drought affects seed development and its quality (Reddy et al., 1994).

Moisture-stress timing and severity during flowering decreases the number of flowers and delays the time to flower. However, since only $15-20 \%$ of flowers form pods, reduction in flowering due to moisture stress does not directly influence pod yield (Nageswara Rao et al., 1988). Also, groundnut can compensate for reduced flower numbers arising from water deficits by producing a flush of flowers once the stress is relieved (Pallas et al., 1979; Nageswara Rao et al., 1988). Soil water deficits during pegging and pod set decrease yield primarily by reducing pod number rather than seed mass per pod (Boote et al., 1976), which is true only if there is sufficient water available for the production of assimilates at the later stage (Harris et al., 1988). Owing to the subterranean fruiting habit of groundnut, a reduction in soil water content can have a dual effect on peg and pod development. While the root-zone water content can directly affect plant water status and photosynthesis (and hence assimilate supply to developing pegs and pods), the water content in the pegging and podding zones can affect reproductive growth independent of the root-zone moisture content. The pod-zone water content influences peg pene-

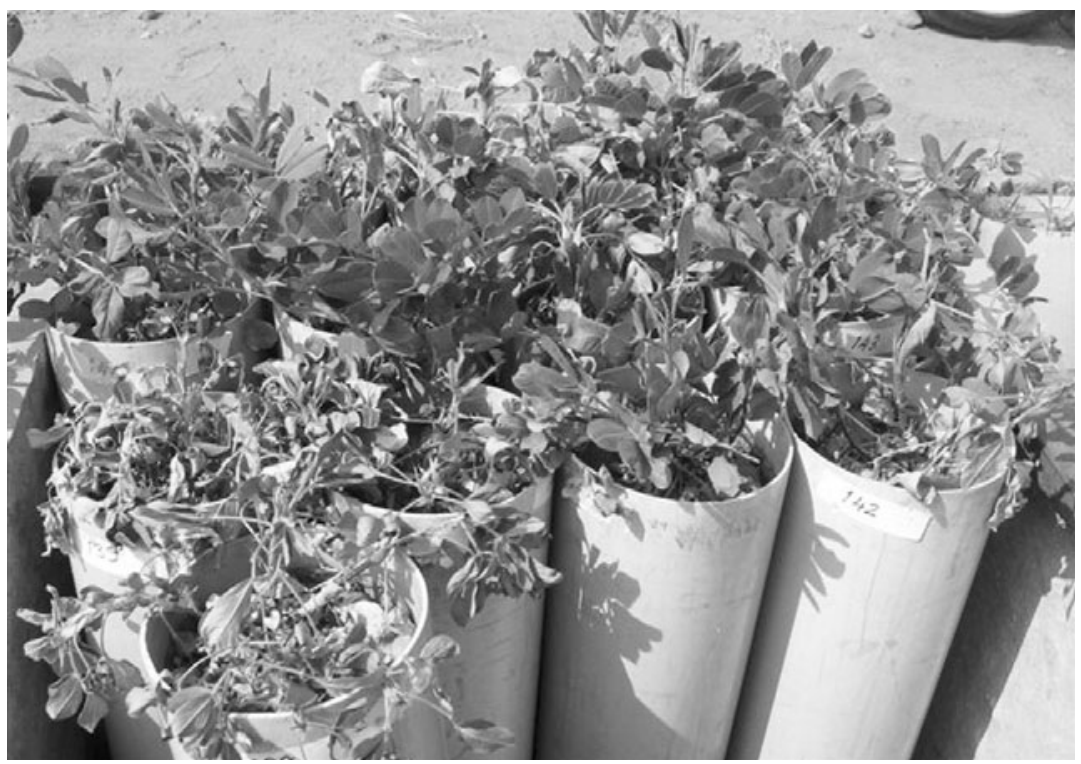

Fig. 8.1. Contrast among groundnut genotypes for early water use and wilting. 
tration and conversion into pods, and calcium and water uptake by pods (Boote et al., 1982).

Variability for maturity duration in groundnut germplasm offers the possibility of selecting genotypes with desired phenology to match the environment. In the regions where the growing season is longer, cultivars belonging to the Virginia type are generally cultivated; in areas where the season is shorter, Spanish and Valencia types are cultivated. With the perceivable changes in global temperature and rainfall patterns, it may become necessary to match genotypes more carefully to the length of growing season. For example, groundnut production in Nigeria has reduced drastically over the past few years because of severe droughts. The isohyets movement towards the south has resulted in the shortening of the period of useful rains in northern Nigeria. This has necessitated the shift from growing long-duration genotypes to short-duration genotypes (Gibbons, 1978). Agroclimatological analysis of major rainfed (75-90 days) groundnut environments in the SAT indicates that growing areas in the SAT are characterized by short growing seasons, i.e. 75-110 days (Virmani and Singh, 1986). This explains the better performance of short-duration genotypes in West African regions.

\section{Chickpea}

Characterizing drought in post-rainy season crops such as chickpea is relatively simple, compared with the intermittent drought experienced by the rainy-season crops. As the crop is grown almost entirely on stored soil moisture, it is exposed mostly to progressively increasing (terminal) water deficit. Factors governing crop growth and water use in the post-rainy season, i.e. radiation, temperature, vapour pressure and potential evaporation, are relatively stable and predictable. Hence simulation modelling of both crop growth and the effects of various crop traits is eminently feasible.

\section{Pigeonpea}

Throughout the SAT regions of South Asia and Africa, where much of the pigeonpea is grown, rainfall is erratic in its amount and distribution. However, based on the long-term rainfall pattern, it is possible to broadly characterize patterns of drought in a given environment by calculating probabilities of dry periods followed by wet periods or vice versa (Virmani et al., 1982). This assessment is helpful in developing genotypes for target environments or in identifying environments with similar drought patterns. Traditionally, medium- to long-duration landraces have been cultivated, with a crop duration of 150-300 days. Pigeonpea can be exposed to intermittent drought stress during dry periods of the rainy season and to terminal drought stress in the post-rainy season. Since the late 1980s, short-duration genotypes have been developed, with extra-short-duration genotypes able to reach maturity within 90 days ( $\mathrm{Nam}$ et al., 1993). However, the short-duration genotypes are usually sensitive to intermittent drought. A pigeonpea simulation model (Robertson et al., 2001) could also facilitate characterization of drought patterns for environments where longterm weather data is available.

\section{Phenotypic Screens and Natural Genetic Variations for Drought Tolerance}

\section{Pearl millet}

The line-source sprinkler irrigation method, earlier developed by Hanks et al. (1976), is used to screen pearl millet for drought tolerance. It provides gradients of drought stress, which allows the evaluation of large numbers of genotypes at varying intensity of drought in a given environment. However, where response to applied water is linear, simpler stress/no stress techniques provide a more efficient means of conducting preliminary evaluations (Mahalakshmi et al., 1990).

When yield performance under stress is not related to time to $50 \%$ flowering, the drought susceptibility index (DSI) is calculated based on yield under rainfed conditions and potential yield under irrigated conditions (Fisher and Maurer, 1978). The lower the DSI, the greater is the drought tolerance. Bidinger et al. (1987a,b) modified the DSI method to include cases in which yield under stress was related to drought escape and yield potential; it was thus used for screening pearl millet and identifying tolerant genetic material.

Grain yield in pearl millet can be improved under water-limited environments if specific 
traits and responses associated with drought tolerance can be identified and incorporated into elite high-yielding genotypes of appropriate crop duration (Bidinger et al., 2000; Yadav et al., 2002). The drought-tolerant lines in pearl millet include 863B, ICMP 83720, ICMV 94472 and PTRLT 2/89-33.

\section{Sorghum}

At the International Crops Research Institute for the Semi-Arid Tropics (ICRISAT), Patancheru, India, sorghum is evaluated for post-flowering drought tolerance during the post-rainy season. The drought is imposed at flowering/grain development stage by withholding water and lines scored for stay-green trait using curvefitting of green leaf area retention and/or leaf chlorophyll content (using Minolta Chlorophyll Meter SPAD 502) at regular time intervals. Promising accessions from the field evaluations are further tested for drought response and root traits using a lysimetric system where plants are grown in large and long PVC cylinders, mimicking roughly the soil volume that sorghum plants would have at the usual field planting densities. The plants are grown under well-watered conditions until booting, after which a waterstress treatment is imposed.

Drought-tolerant sources in sorghum include Ajabsido, B35, BTx623, BTx642, BTx3197, El Mota, E36Xr16 8/1, Gadambalia, IS12568, IS22380, IS12543C, IS2403C, IS3462C, CSM-63, IS11549C, IS12553C, IS12555C, IS12558C, IS17459C, IS3071C, IS6705C, IS8263C, ICSV 272, Koro Kollo, KS19, P898012, P954035, QL10, QL27, QL36, QL41, SC414-12E, Segaolane, TAM422, Tx430, Tx432, Tx2536, Tx2737, Tx2908, Tx7000 and Tx7078 (www.icrisat.org). Drought tolerance of M 35-1, a highly popular postrainy-season-adapted landrace in India, has been demonstrated (Seetharama et al., 1982).

\section{Maize}

Various options have been used for screening the germplasm for identification of relative tolerance to water-limited conditions (Bruce et al., 2002). Growth chamber or greenhouse screening may provide highly precise management of intensity, uniformity and timing of stress treatment. However, the findings may have least repeatability in target population environments, which closely represent farmers' fields. These evaluations generally require multiple seasons and a large number of sample environments for judicious judgement on the performance of a cultivar in target environment. Statistical procedures such as genetic correlation among environments, genotype $\times$ environment interaction and stability analysis can help improve the process of establishing the reliability of prediction on the performance of genotypes in target population environments (Cooper and DeLacy, 1994).

Managed-stress environments under rain-free season may play an essential role in assuring reproducible stress conditions targeted at specific growth stages. At CIMMYT (International Maize and Wheat Improvement Center), genotypes are screened under three moisture regimes: (i) well watered, where moisture is maintained in the plots as per normal recommendation; (ii) intermediate water stress, where plants are exposed to drought stress during late flowering and throughout grain filling by withdrawing irrigation 1 week before flowering until maturity; and (iii) severe stress, where plants are exposed to drought stress during flowering and the early grain-filling stage by withdrawing irrigation 3 weeks before flowering. Each of the managed moisture conditions is able to expose genetic variation for specific traits. The well-watered condition allows expression of yield potential; the intermediate water-stress regime exposes genetic variation for lower leaf senescence and grain yield; and the severe stress regime exposes the variability for ASI and ears per plant. Selection for drought tolerance is based on grain yield, ASI, ears per plant, stay-green and tassel size, which have shown tremendous gains across the moisture regimes (Edmeades et al., 2000).

The sources of drought tolerance in maize include 95TZEE-W, 95TZEE-Y, Ac7643, Ac7643S $_{5}$, Chang 3, CML 269/CML343, CML 449/CML 343, D 978, Danhuang 02, HI 209, HI 295, HI 536, HI1040, K 10, K 22, TSC 8, TZE-COMP 3 DT, X178, Xi 502, Ye 8001, Yedan-13 and Zheng 22 (www.cimmyt.org) (Fig. 8.2). 


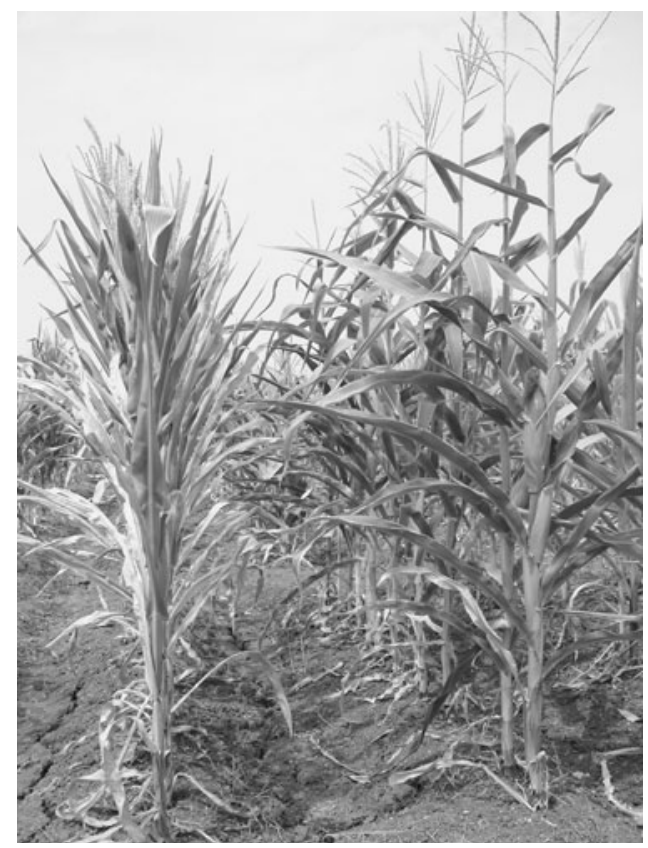

Fig. 8.2. Available genotypic variability for flowering-stage drought stress in tropical maize.

\section{Groundnut}

ICRISAT adopted a holistic approach in screening and selecting groundnut genotypes with superior performance under mid-season and end-of-season drought conditions (Nageswara Rao and Nigam, 2003). An empirical approach was first followed for selection among segregating populations and evaluation of advanced breeding lines for their sensitivity to mid-season and end-of-season droughts, based on pod and seed yields. While the empirical approach was partly successful, it was concluded that a more efficient breeding approach is required for the selection of traits associated with drought tolerance. There has been significant improvement in physiological understanding of the genotypic response to drought in groundnut, suggesting scope for selecting genotypes with traits contributing to superior performance under waterlimited conditions. For instance, substantial genetic variation has been observed in partitioning of dry matter to pods (Nageswara Rao et al., 1993). Significant genotypic variation in the total amount of water transpired $(\mathrm{T})$ and transpiration efficiency (TE) has been shown
(Wright et al., 1994). Further studies have confirmed large cultivar differences in TE in groundnuts (Hubick et al., 1988; Wright et al., 1994). These studies enabled analysis of the yield variation under drought conditions using a physiological framework proposed by Passioura (1977), where HI = Harvest Index:

$$
\text { Pod yield }=\mathrm{T} \times \mathrm{TE} \times \mathrm{HI}
$$

Research has also shown that TE and carbon isotope discrimination in leaf (CIDL) are well correlated (Wright et al., 1988), suggesting the possibility of using CIDL as a rapid, nondestructive tool for selection of TE in groundnut. However, further research has shown that specific leaf area (SLA), expressed in $\mathrm{cm}^{2} / \mathrm{g}$, is well correlated with CIDL and TE (Wright et al., 1994).

Several sources of tolerance to mid-season and/or end-of-season drought have been reported in groundnut that showed variation for physiological traits such as SLA, WUE, T, TE, and $\mathrm{HI}$ under drought-stress conditions (Dwivedi et al., 2007a). Rucker et al. (1995) identified a drought-tolerant, high-yielding line, PI 315628, from pot/field experiments, with the largest root system and low in-canopy temperature.

\section{Chickpea}

Both line-source and DSI methods have been found to be very effective in identifying sources of tolerance to terminal drought in chickpea. Sources of drought tolerance identified by the first method (Saxena, 1987) were further validated by the second method (Johansen et al., 1994). The drought-tolerant chickpea accessions include Annigeri (high yield and short duration), ICC 4958 (large root, large seed, rapid partitioning), ICC 10448 (high yield, smaller pinnule, large sink), ICC 5680 (small leaf, fewer pinnules) and JG 62 (twin-podded, rapid partitioning) (Saxena et al., 1993; Saxena, 2003). Kashiwagi et al. (2006) perfected a PVCcylinder-based technique for screening chickpea root traits associated with drought tolerance. Root length density (RLD) at 35 days after sowing showed significant positive correlation with seed yield. Similarly, RLD at different soil depth (15-30 or 30-60 cm) had positive effects on seed yield, more pronounced under severe 
drought. RLD of plants grown in cylinders with $70 \%$ field capacity correlates well with RLD in the field trials. Using this technique, Kashiwagi et al. (2005) detected substantial variation in root-length density (RLD) in chickpea landraces collected from the Mediterranean and West Asian regions that showed better drought tolerance than of the known drought-tolerant genotype, ICC 4958. Promising drought-tolerant breeding lines/cultivars include ICCVs 94916-4, 94916-8, 94920-3, 94924-2, 94924-3, and 98901 to 98907 , with yields similar to the highyielding parent (Saxena, 2003).

\section{Pigeonpea}

The rainout shelter facility at ICRISAT has significantly improved the precision of drought screening. Chauhan et al. (1998) detected substantial genetic differences when they screened 32 pigeonpea lines for drought tolerance at flowering using DSI. ICPL 88039 showed greater drought tolerance than other genotypes. Pigeonpea hybrids ICPH 8 and ICPH 9 were the most drought tolerant and their reaction was further confirmed in multi-location trials.

The drought screening under the rainout shelter, though reliable, has limitations of space and that pigeonpea cannot be grown year after year at the same place. To overcome the latter problem, rainout shelters that can be moved to different places have been designed (Chauhan et al., 1997).

Breeding programmes on pigeonpea in recent years have focused on developing genotypes of 90-150 days maturity (Gupta et al., 1989). This has made it possible to match phenology with periods of soil moisture availability, a proven way of combating terminal drought (Chauhan et al., 1998). Nevertheless, there is considerable yield gap, which is largely due to the adverse effect of intermittent droughts in different environments (Nam et al., 1993). The short-duration pigeonpea and extra-short-duration pigeonpea cultivars are generally shallow rooted (Chauhan et al., 1993), and what they gain by being able to escape terminal drought stress is lost by their inability to extract water from the deeper soil layer. Indeed it is observed that these genotypes extract water from shallower $(<75 \mathrm{~cm})$ layers, compared with an unstressed control (Nam et al., 2001). In addition, large gaps within the rainy-season rainfall are not unusual in the semi-arid regions, when extra-short-duration and short-duration cultivars may be forced to grow with limited ability to extract water due to their shallow root system. Therefore, more work is needed for screening and selecting pigeonpea cultivars for intermittent drought tolerance.

\section{Genetic Enhancement for Improved Water Productivity}

\section{Drought escape}

\section{Pearl millet}

Drought escape is a major mechanism in pearl millet, determining relative cultivar performance in individual stress environments (Bidinger et al., 1987a), often a major cause of genotype $\times$ environment interaction in multi-environment trials (van Oosterom et al., 1996). For example, if rains end early, a 1-week difference in time to flowering between two cultivars is equivalent to about $30 \%$ of the grain-filling period, which enables an early flowering cultivar to escape stress (Mahalakshmi et al., 1988).

The effects of timing of the occurrence of individual periods of stress, before and after flowering provide quantification of the effects of drought escape. For example, an early genotype which flowered 20 days before the onset of a terminal drought stress had about one-quarter of the yield reduction $(-12 \%$ versus $-51 \%)$ of a genotype that flowered only 10 days before the onset of the same stress (Mahalakshmi et al., 1987). However, the scope for using this mechanism in crop improvement under drought conditions still depends upon the predictability of the occurrence of stress.

\section{Sorghum}

Breeding for earliness has been successful for increasing the yield of rainy-season sorghums in India (Seetharama et al., 1982). Earliness is more advantageous during the post-rainy season, although crop maturing earlier than 3 months may not achieve high yields (Seetharama et al., 1982). In West Africa, phenotypic plasticity 
derived from photoperiod sensitivity is an important adaptive trait, useful for matching the crop growth and development with the wateravailability period.

\section{Groundnut}

In most of the groundnut-growing regions in the SAT, the rainfall distribution is erratic and the season length is less than 100 days (Virmani and Singh, 1986). Considerable progress has been made at ICRISAT in shortening the crop duration of groundnut without decreasing the realized yield substantially (Vasudeva Rao et al., 1992). The short-duration varieties developed at ICRISAT have shown superior pod yield over local control varieties in several countries. The early-maturing genotypes usually have shallow root systems, which could make them more susceptible to intermittent drought and also result in reduction of the yield potential. However, genotypic differences in rooting depth have been observed in groundnut (Wright et al., 1991; Nageswara Rao et al., 1993), suggesting the scope for combining early maturity with efficient root system.

\section{Chickpea}

Short-duration varieties that mature before the onset of terminal drought have proved successful in increasing yield under drought-prone conditions in chickpea (Kumar et al., 1996). However, since seed yield is generally correlated with the length of crop duration under favourable crop-growing conditions, reduction of crop duration below the optimum would have a yield penalty (Saxena, 1987). Depending upon the water availability, optimum crop duration for maximum yield would vary. Hence, varieties need to be matched with the length of growing period (Fig. 8.3). Significant progress has been made in developing improved short-duration chickpea varieties that mature in 80-90 days (Kumar et al., 1996) and extra-short-duration varieties ( $<80$ days), which provide options to grow chickpea in many prevailing systems and evolving new production systems, such as rice fallows (Kumar and van Rheenen, 2000).

\section{Pigeonpea}

Studies indicate that terminal drought usually reduces the grain yield of landraces growing in their typical environment (Chauhan et al., 1992). This is more apparent in the shorterduration environments closer to the equator, where evapotranspiration is high during the post-rainy season. Thus, in terms of maximizing grain yield, the duration of these landraces seems too long for the period of soil moisture availability. However, there is a large spectrum

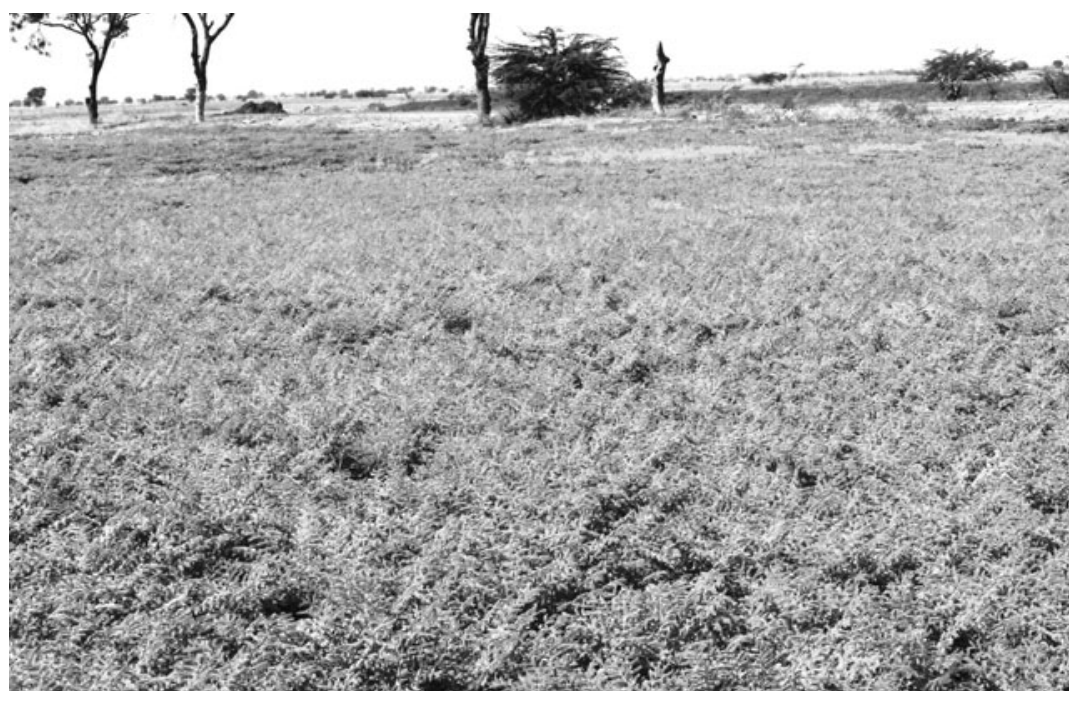

Fig. 8.3. An extra-short-duration chickpea variety that escapes terminal drought. 
of genotype duration available (Gupta et al., 1989), and matching genotype duration with likely period of soil water availability ensures against terminal drought stress. Further, opting for a shorter-duration cultivar in a region does not necessarily mean a sacrifice in yield potential, as even extra-short-duration pigeonpea varieties can produce yields above $2.5 \mathrm{t} / \mathrm{ha}$ (Nam et al., 1993).

\section{Candidate traits for drought tolerance}

\section{Pearl millet}

The panicle HI, i.e. the ratio of grain to total panicle weight, has been evaluated as a selection criterion for terminal stress tolerance in pearl millet breeding (Bidinger et al., 2000). It is also currently used as one of the traits for which quantitative trait loci (QTLs) are being identified, from a mapping population made from parents that differ in the ability to maintain panicle $\mathrm{HI}$ under stress. Panicle HI, however, is readily and inexpensively measured in field experiments and can be used as a direct selection criterion. The main potential benefit to identifying QTLs for panicle HI would be to allow marker-assisted backcross transfer of improved tolerance of terminal stress to elite lines and varieties, without the requirement for extensive field screening (Fig. 8.4).

\section{Sorghum}

Delayed senescence or stay-green is considered as a useful trait for plant adaptation to postflowering drought stress, particularly in environments in which the crop depends largely on stored soil moisture for grain-filling (Fig. 8.5). Morphological traits associated with drought endurance and escape in sorghum include good seedling emergence and vigour, earliness, staygreen, tillering, pollination gap, better seed set and grain-filling, good panicle exsertion and reduced stalk lodging. Glossy trait in sorghum, characterized by light yellow-green leaves with a shiny surface, has been reported to confer a broad-spectrum tolerance to both biotic and abiotic stresses, including drought, high temperature, salinity, diseases and insects (Maiti, 1996). The glossy leaf surface is believed to be due to

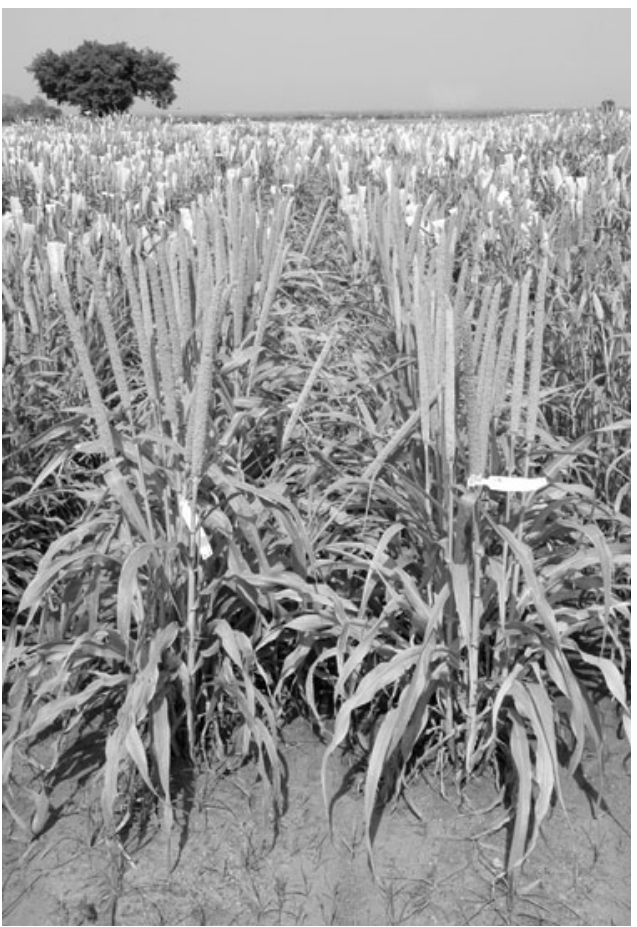

Fig. 8.4. Good seed set in the long-panicle pearl millet varieties adds to drought tolerance.

epicuticular wax. The majority of the 495 accessions with glossy trait identified at ICRISAT are from the Indian peninsula and belong to the taxonomic race durra. Many of the genotypes tolerant to drought at the seedling stage are glossy and recover faster once the stress is relieved (Maiti et al., 1984).

\section{Maize}

Grain yield is commonly used as a selection criterion in crop improvement. However, inheritance of yield is complex and its heritability often declines under stress conditions (Bolaños and Edmeades, 1996). Selection on the basis of grain yield per se for improved performance under abiotic stresses has often been misleading and inefficient. Therefore, stress breeding programmes commonly use secondary traits, where heritability of some of these traits, such as ASI and ears per plant, remains relatively high, while the genetic and phenotypic correlations between grain yield and those traits increase sharply under drought and low nitrogen stresses (Bolaños and 


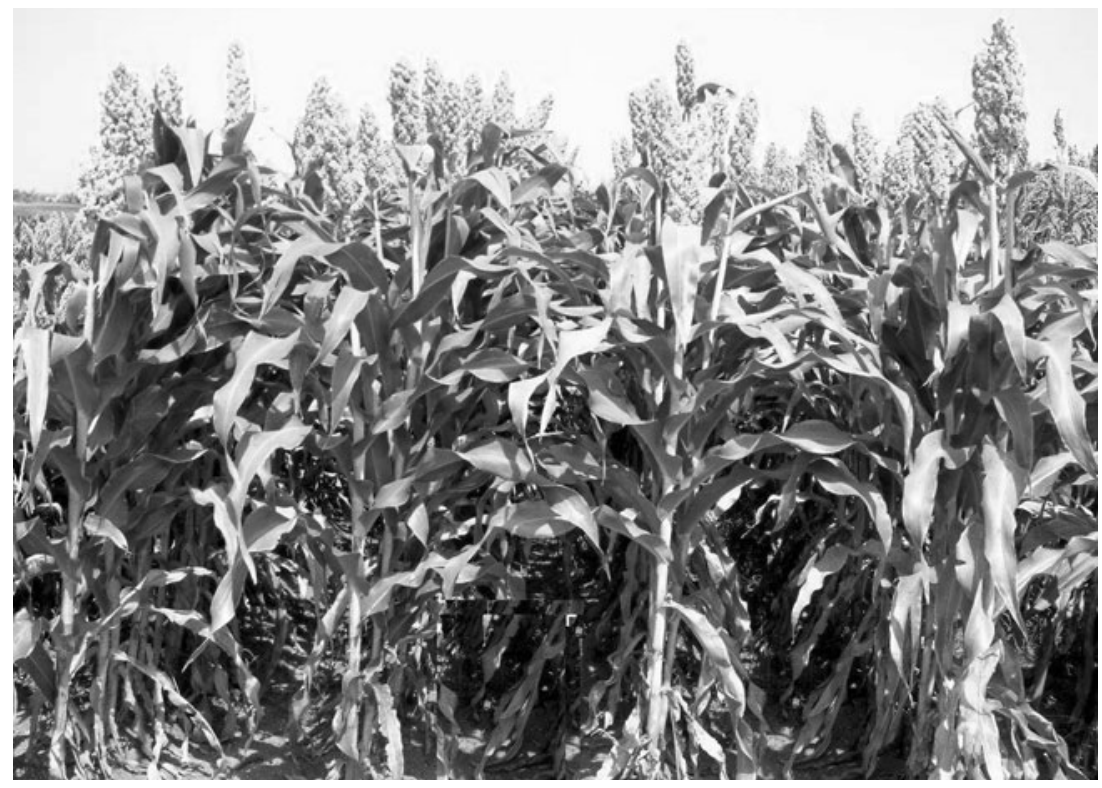

Fig. 8.5. The stay-green trait provides enhanced drought tolerance in sorghum.

Edmeades, 1996; Banziger et al., 1997). Edmeades et al. (1998) suggested that an ideal secondary trait should be: genetically associated with grain yield, highly heritable, genetically variable, cheap and fast to measure, stable within the measurement period, not associated with a yield penalty under unstressed conditions, easily observed at or before flowering in order to eliminate undesirable parents from being used in crossing, and a reliable estimator of yield potential before final harvest.

Key secondary traits for selecting drought tolerance include reduced barrenness on ears, ASI, stay-green, and to a lesser extent, leaf rolling (Banziger et al., 2000c). Other traits such as root growth are only useful when they have been field-tested and have met the criteria prescribed for an ideal secondary trait. Roots have a very important role in water acquisition and a significant component of tolerance to water-deficit stress (McCully, 1999). When studying the relationship between early root development and grain yield under drought using recombinant inbred lines (RILs) differing in seedling root traits, the RILs with poorer early root development yielded better than those with more vigorous early root development (Bruce et al., 2002). Using stress-adaptive secondary traits along with grain yield in maize has improved the selection gain in yield under low nitrogen stress by $20 \%$ in comparison to selection for yield per se (Banziger et al., 1997).

\section{Groundnut}

Good scope exists for genetic improvement of the efficiency of crop water use in groundnut (Wright and Nageswara Rao, 1994). Significant genotypic variations in $\mathrm{T}$ and TE have been reported in groundnut (Wright et al., 1988) (Fig. 8.6). Groundnut lines ICGS 76, ICGS 44, Tifton 8 and Kadiri 3 were identified with high TE values (Wright et al., 1994). The extent of the root depth and RLD becomes important for soil water extraction during prolonged water deficit. Deep rooting and faster extraction may be very appropriate in tropical environments, where groundnut is grown solely on stored moisture in the dry season on high water-holding capacity soils (Prabowo et al., 1990). Genotypic variability for root characteristics (root volume, root dry weight, root length and number) has been reported in groundnut (Ketring, 1984). However, only minor differences in water extraction patterns and total water use were observed among cultivars (Wright and Nageswara Rao, 1994). 


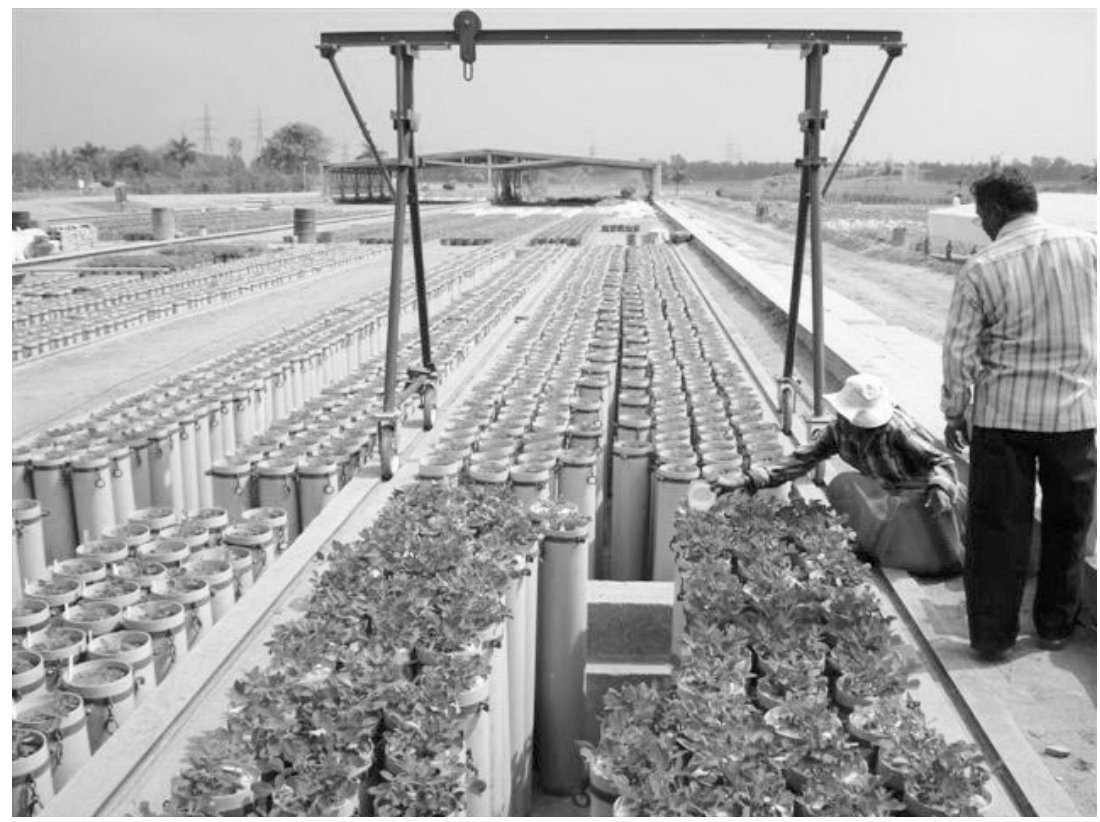

Fig. 8.6. Characterization of the variation in transpiration across growing time of the reference collection of groundnut germplasm using a mini-lysimetric system.

\section{Chickpea}

Two important drought-avoidance traits have been characterized and widely used for the genetic enhancement of chickpea at ICRISAT: the large root system (which appears to be useful in greater extraction of available soil moisture) and smaller leaf area (which has been shown to reduce the transpirational water loss) (Fig. 8.7). The chickpea line ICC 4958 has multiple traits of large root size, a rapid rate of root development and extraction of water, and a rapid rate of seed development related to its large seed size. Lines ICC 5680 and ICC 10480 have smaller leaf area, owing to either narrow pinnules (ICC 10480) or fewer pinnules (ICC 5680). Recombinants with traits of ICC 4958 and ICC 5680 showed higher midday leaf relative water content compared with the parents in field trials conducted at ICRISAT (Saxena, 2003).

End-of-season drought is often associated with increasing temperature (Calcagno and Gallo, 1993). Early pod set is considered a prime strategy for avoiding drought stress in environments prone to end-of-season moisture stress (Sedgley et al., 1990). The development of early-maturing varieties may help drought escape and result in stabilizing productivity and assist in extending the chickpea crop to more drought-prone areas.

\section{Pigeonpea}

Several mechanisms seem to contribute to adaptation of pigeonpea to drought, which in some cases ensure only its survival but in other cases also have an effect on grain yield. These have been categorized under three strategies: (i) drought escape (e.g. phenological adjustment); (ii) drought avoidance (e.g. deep root systems, stomatal closure, leaf shedding and rolling, paraheliotropic movement, low epidermal conductance); and (iii) drought tolerance (osmotic adjustment, radiation use efficiency, photosynthesis, partitioning of assimilates). Important putative drought-tolerance traits for pigeonpea include early vigour, leaf area maintenance, high root and shoot growth rate, and development plasticity (Johansen, 2003). Early growth vigour is an important factor in drought 


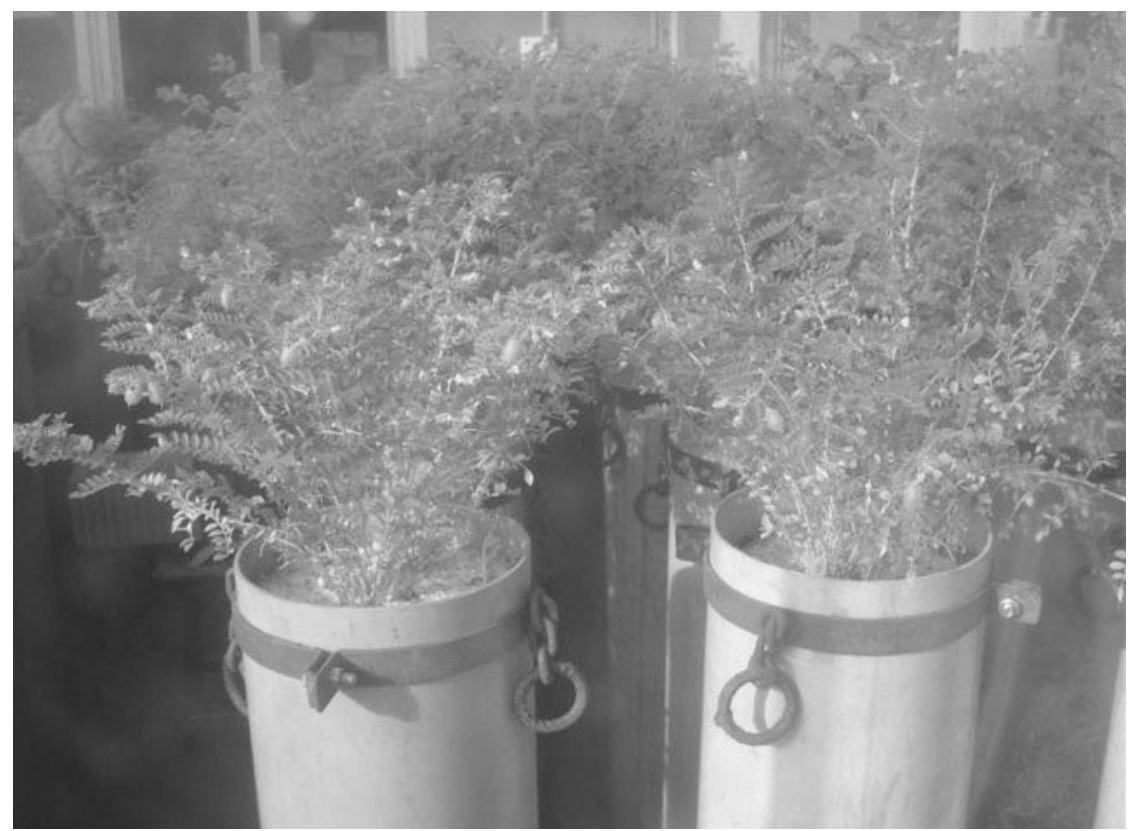

Fig. 8.7. Evaluation of chickpea germplasm for transpiration variability by use of a mini-lysimetric system.

resistance as it permits establishment of an effective root system that can extract water during later drought periods. There are considerable differences in early growth vigour of pigeonpea (Johansen, 2003). Early-maturing genotypes generally show more vigour than latermaturing ones, with hybrids showing most vigour, but there are exploitable differences in this trait within maturity groups.

While reduction in leaf area under drought stress would reduce transpirational losses and thus enhance survival ability, leaf area maintenance seems to be an important consideration for pigeonpea under drought (Subbarao et al., 1995). Leaf area maintenance under intermittent drought stress would involve an integration of several lower-level traits, such as a root system effective in water extraction, dehydration tolerance and leaf movements. Leaf area maintenance can be used as morphological marker in a breeding programme. Pigeonpea shows large genotypic differences for this trait (Lopez et al., 1997). The short-duration genotype ICPL 87 performs better than its sister genotype, ICPL 151, which correlates with the greater leaf area retention of ICPL 87 under drought than ICPL 151.

\section{Empirical and Trait-based Approaches to Enhance Drought Tolerance}

Plant breeding provides a means of closing the gap between actual and potential yield in stressed environments (marginal and dry areas) through genetic manipulations (Acevedo and Ferreres, 1993). Crops, or cultivars within each crop, are replaced with others having a higher fitness in an environment gradient arising from uncontrolled physical limiting factors. Hence, farmers and breeders attempt to identify crop tolerance in these gradients arising from the specific abiotic stresses. However, the choice of the crop or cultivars within a crop in terms of 'economic phenotype performance' are driven by several intricate factors such as genotype, environment, crop management, policies (affecting both people and market), institutional arrangements and social demographics, which make the plant breeders' job much more complicated (Ortiz et al., 2002).

\section{Pearl millet}

Grain yield potential has been considered as a significant factor in determining the yield under 
moisture stress conditions as well (Bidinger et al., 1982; Fussell et al., 1991). Improvement in yield potential is expected to result in some improvement under moisture stress, especially under terminal stress and less severe stress conditions. However, this could not be validated under natural drought conditions during the main rainy season (Yadav and Weltzien, 1999). Breeding for wide adaptation has also resulted in selecting genotypes with drought tolerance, such as ICTP 8203 (in India), IKMP 3 and IKMP 5 (in Burkina Faso).

Considerable research has been conducted on the traits themselves, but there are few cases where an individual trait or mechanism has been shown to be sufficiently associated with yield to recommend it as a selection criterion (Mahalakshmi et al., 1997). In pearl millet, ability to set and fill grains was found to be related to drought tolerance (Bidinger et al., 1987a). Of all the responses related to drought tolerance in pearl millet, panicle $\mathrm{HI}$ (ratio of grain mass to the total panicle mass), which integrates both setting and filling of grains, was the best predictor. Therefore, panicle $\mathrm{HI}$ can be used as an inexpensive selection criterion in breeding for drought conditions in pearl millet. Panicle $\mathrm{HI}$ is a particularly effective variable for post-flowering stress, because the mass of the structural parts of the panicle (which complete their growth prior to flowering) is largely unaffected by stress, whereas the grain mass is significantly affected by both floret abortion and reduced grain-filling (Bidinger and Mukuru, 1995). However, the analysis of predicted response to selection for panicle $\mathrm{HI}$ did not indicate that panicle $\mathrm{HI}$ would be an effective indirect selection criterion for improved yield under stress in the test-crossed mapping population lines. This is in contrast to the results achieved in the actual selection experiments. This suggests that the requisite (genetic) preconditions for panicle $\mathrm{HI}$ to be an effective indirect selection criterion for improved terminal stress tolerance need to be clearly defined.

\section{Sorghum}

Breeding for drought tolerance could be linked either to drought-resistance mechanisms and/or to yield. At ICRISAT, a combination of these two approaches with pedigree selection is followed. The drought-tolerant lines selected under mild stress showed high yield potential in stress-free environments; thus it is possible to select for drought tolerance without a concomitant yield decrease in non-stress environment (Rosielle and Hamblin, 1981).

Selections for yield and wide adaptation, determined on the basis of multi-location testing, may or may not be useful in selecting for drought tolerance as the nature, severity and duration of drought stress vary with soil type and weather variables. There is, therefore, a need for a wide range of cultivars and fine-tuning at local levels. Higher green leaf area, delayed onset of leaf senescence, and reduced rate of leaf senescence have been suggested to improve yield under terminal drought situations (Hammer and Muchow, 1994). An approach to breeding for drought tolerance and yield potential at ICRISAT includes: (i) selecting breeding materials for specific traits such as emergence under soil crust; (ii) seedling drought recovery, and grain yield under drought-prone and high-potential areas for early-stage drought; (iii) drought recovery for grain yield under drought-prone and high-potential areas alternatively for mid-season drought; and (iv) stay-green, non-lodging and grain yield under drought-prone and high-potential areas alternatively for terminal drought (Reddy, 1986).

Sorghum hybrids are known to have reduced growth duration, due to higher growth rates, and increased HI (Blum et al., 1977), and earlymaturing genotypes have shown relative yield advantage under late-season moisture stress (Saeed and Francis, 1983; Saeed et al., 1984). Selection for improved productivity under water-stress conditions resulted in a genetic shift towards early flowering but with some yield penalty. Nevertheless, the increased yield potential coupled with greater vigour and earliness of hybrids has been very well exploited to breed for drought tolerance through escape mechanism. The rainy-season hybrids rapidly became the primary components of various production systems in India because of their higher productivity, wider adaptability, short duration and stature (Rana et al., 1997). Under terminal water stress during the post-rainy season, earlymaturing sorghum genotypes produce equal grain but less dry matter than late-maturing cultivars. Some popular sorghum hybrids with 
higher water productivity include $\mathrm{CSH} 8, \mathrm{CSH}$ $18, \mathrm{CSH} 16$ and JKSH 22. The superior performance of sorghum hybrids over varieties in semi-arid dry areas has been demonstrated in several countries (Kebede and Menkir, 1987; House et al., 1997). Hybrids perform better than varieties under moisture conditions, and also recover faster when moisture stress is released (Osmanzai, 1994).

The stay-green trait expresses best in environments in which the crop is dependent on stored soil moisture but where this is sufficient to meet only a part of the transpiration demand. Sufficient expression of the trait for selection is thus dependent upon the occurrence of a prolonged period of drought stress of sufficient severity during the grain-filling period to accelerate normal leaf senescence but not of sufficient magnitude to cause premature death of the plants (Mahalakshmi and Bidinger, 2002). The stay-green trait from IS 12555 (SC 35) has been successfully used in Australia to develop postflowering drought tolerance and lodging resistance in parental lines and commercial hybrids (Henzell et al., 1992). Conventional breeding for stay-green has been primarily based on B 35 and KS 19 (Mahalakshmi and Bidinger, 2002). The partially converted (B 35) and fully converted (SC 35C-14E) versions of IS 12555 (Rosenow et al., 1983) have provided the best sources of the trait used in the Australian programme (Henzell et al., 1997). Sorghum hybrids containing the stay-green trait yield significantly more under water-limited conditions compared with hybrids not possessing this trait (Rosenow et al., 1983; Borrell and Douglas, 1996). This advantage is reported to be due to maintenance of photosynthetic capacity and reduced mobilization of stem reserves to grain during the late grain-filling period, combined with lodging resistance (Borrell and Douglas, 1996). In this study, stay-green was not associated with lower HI, as was reported in an earlier study (Rosenow et al., 1983).

\section{Maize}

Plant breeders traditionally evaluate their advanced materials in a range of environments. The approach relies on multiple tests of progenies in the environments representing a random selection of the variation in drought stress in the target environment and selection largely on the basis of grain yield (Rosielle and Hamblin, 1981). More recently, Zaidi et al. (2004) have demonstrated that with conventional selection under optimal conditions it is likely that some of the best materials with tolerance to drought and/or lownitrogen stress might have been rejected, while other less desirable materials for marginal and less favourable environments are selected on the basis of their superior performance under optimal input and favourable environments. Plant response to limited water conditions in terms of drought-adaptive traits is only expressed when they are exposed to such conditions, and genetic variability can be identified. Castleberry et al. (1984) examined Corn Belt hybrids developed under optimal input conditions from a period of more than 50 years and found very low selection gains under low soil fertility. Similarly, MartinezBarajas et al. (1992) reported that progress from selection for high yield under well-watered conditions was greatly reduced under water-deficit conditions. These results suggest that positive spillover effects from selection under optimal conditions to stress conditions may be limited. Duvick (1995) proposed that the major goal of the tropical maize improvement programme should be to improve and stabilize yield, and broaden adaptation through increased tolerance to various abiotic stresses. For areas where the average maize yield is less than $2.0-2.5 \mathrm{t} / \mathrm{ha}$, selecting genotypes for high yield in these target environments is preferred (Fig. 8.8).

While comparing the suitability of managedstress versus multi-location testing for improving drought tolerance in maize, Byrne et al. (1995) concluded that evaluating the genotypes under managed drought stress, rather than that which occurs randomly during multi-location testing, is relatively more effective and efficient in selecting maize germplasm for water-deficit tolerance. Elapsed time per selection cycle is often less when testing under a few managed environments than under multi-location testing at several sites. Use of modern experimental designs, such as alpha lattices or row and column designs, can further increase selection efficiency (Yau, 1997). Relating the environmental classification, crop modelling and the identification of the target population environments the crop encounters over time suggests 


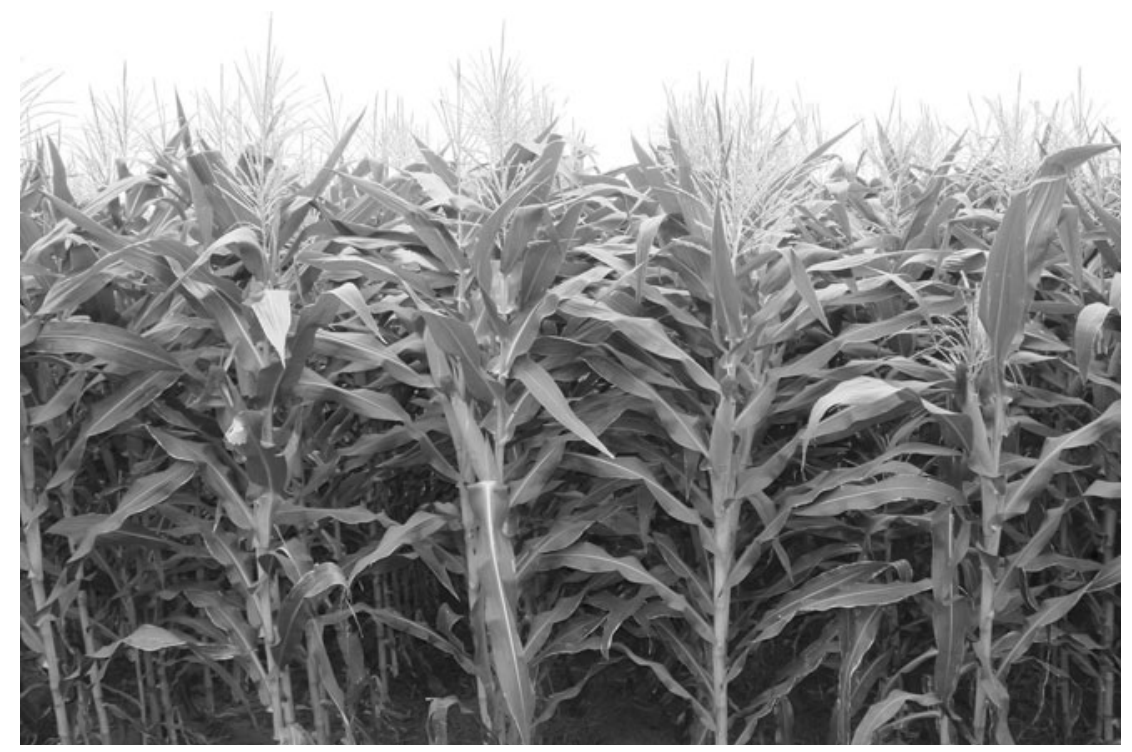

Fig. 8.8. A high-yielding CIMMYT maize hybrid at ICRISAT campus.

that considerable gains can be expected in this area (Chapman et al., 2000).

\section{Recurrent selection for drought tolerance}

CIMMYT has made a concerted attempt to select and improve mid-season drought tolerance in tropical maize and identified 50-80 best-performing families that produced high grain yield across the water-stress regimes, small ASI and delayed foliar senescence under severe and intermediate stresses, and adequate yield and small tassels under well-watered conditions (Byrne et al., 1995).

Edmeades et al. (1994) demonstrated that gain in yield across two populations (La Posta Sequia and Pool 26 Sequia) averaged $259 \mathrm{~kg} / \mathrm{ha}$ (12.4\% per cycle) under drought, and $115 \mathrm{~kg} / \mathrm{ha}$ (1.5\% per cycle) under well-watered conditions. Yield improvements under drought were paralleled by increases in ears per plant (0.075 per cycle) and in HI, while ASI declined (1.3 days per cycle). Principal component analysis of yields in the ten different environments showed that wellwatered and drought environments were generally orthogonal, which indicates that selection only in well-watered environments is unlikely to give improvements in yield under drought. They concluded that selection for drought tolerance has improved broad adaptation, as well as specific adaptation to dry environments. Further studies under two water regimes (well watered and severe drought stress) revealed that yield gains in $\mathrm{La}$ Posta Sequia and DTP (drought-tolerant population) averaged 218 and $239 \mathrm{~kg} / \mathrm{ha} /$ cycle under drought and 55 and $41 \mathrm{~kg} / \mathrm{ha} /$ cycle under wellwatered conditions, respectively. Yield improvements under drought were paralleled by increases in ears per plant and HI, while ASI declined (Srinivasan et al., 2003). Bruce et al. (2002) also reported average improvement in grain yield of $126 \mathrm{~kg} / \mathrm{ha} / \mathrm{cycle}$, following recurrent selection under drought conditions.

\section{Gains from multi-environments evaluation}

Zaidi et al. (2004) examined the performance of hybrids of DTP across stress (drought and low nitrogen) and unstressed environments. The normal single cross (NSC) hybrids were slightly better than DTP topcrosses under unstressed conditions. However, under stressed conditions NSC hybrids performed very poorly. The NSC hybrids yielded only $3.3-4.8 \%$ under drought and 34.8-36.2\% under low nitrogen, while DTP hybrids yielded up to $31.8-42.4 \%$ under drought and $48.9-63.6 \%$ under low nitrogen. Improved performance of DTP hybrids across the environ- 
ments was related to improvements in secondary traits under stress conditions: reduced ASI, increased ears per plant, delayed senescence and relatively high leaf chlorophyll. Correlation and regression analysis showed a strong relationship between grain yield under drought and lownitrogen stress in the germplasm improved for mid-season drought tolerance. However, the relationship was not significant with germplasm improved for yield per se under optimal conditions.

The improved sources from CIMMYT exhibited an equally good level of drought tolerance in Southern Africa, and when introgressed in local germplasm, the newly developed hybrids have shown superior and stable performance across the wide range of growing conditions in Southern and eastern Africa. The openpollinated varieties developed using these source germplasms showed $35 \%$ superiority over commercial hybrids under moderate to severe levels of water stress (Banziger et al., 2000b).

\section{Improved drought tolerance using stress-adaptive traits}

Several traits for drought and low-nitrogen tolerance in maize were evaluated and their value as a secondary trait assessed (Bolaños and Edmeades, 1996; Banziger et al., 1997), and a few traits with proven value in selection for drought tolerance were used extensively for improving maize productivity under limited moisture conditions.

EARS PER PLANT Drought at flowering causes severe barrenness and destabilizes the grain yield. Ability of a genotype to produce an ear under such adverse conditions is certainly an important characteristic of drought tolerance in maize. More than $75 \%$ of the yield variation under drought was accounted for by variation in the number of ears and kernels per plant (Bolaños and Edmeades, 1996; Edmeades et al., 2000). Grain yield under drought stress showed a strong relationship with ears per plant $(r=0.90 \pm 0.14)$ and, across the trials, a strong curvilinear relationship with ears per plant $\left(r^{2}=0.94^{* *}\right)$. Being highly heritable (Bolaños and Edmeades, 1996; Edmeades et al., 2000) and having a stronger relationship with grain yield, ears per plant has been used as a trait in the selection for water-limited environments and is important in the selection index for drought tolerance (Banziger et al., 2000a).

ANTHESIS-SILKING INTERVAL The ASI is a symptom of ear growth rate, and the difference in ASI among genotypes growing in the same environment reflects differences in partitioning efficiency to the ear. The genetic correlation between grain yield and ASI in a diverse array of genotypes grown under drought at flowering is about -0.6 (Bolaños and Edmeades, 1996; Edmeades et al., 2000), and the strong curvilinear relationships observed with yield under severe drought stress suggest that ASI is a visual indicator of underlying processes affecting reproductive success. Recurrent selection for midseason drought tolerance in several diverse tropical maize populations at CIMMYT over two to ten cycles has increased grain yield under stress by about $100 \mathrm{~kg} / \mathrm{ha} /$ year and reduced ASI by 0.6 days/year. Reduction in ASI was associated with decline in spikelets per ear, increase in rate of ear growth, spikelets and silk growth, and increase in $\mathrm{HI}$ (Edmeades et al., 2000).

LEAF SENESCENCE Studies at CIMMYT revealed little adaptive value of this trait because of lack of association between green leaf area longevity and grain yield and the apparent lack of progress in selecting for delayed senescence (Bolaños et al., 1993). Nevertheless, delayed senescence and stay-green is an important trait under drought stress, indicative of plant water status, and is useful for selection of maize genotypes under drought stress, although relatively less weight is given in the selection index (Banziger et al., 2000a). The stay-green characteristic of maize facilitates a long grain-filling period and a long duration of harvesting in silage varieties (Choi et al., 1995). Bekavac et al. (1998) detected highly significant genetic and phenotypic correlations between stay-green, stalk water content, leaf water content, vegetative period and grain moisture in two synthetic maize populations (Syn103NS and Syn140NS), with most consistent genetic correlations established between stay-green and leaf water content $(r=0.85-0.90)$.

TASSEL SIZE The maize plant is a prolific pollen shedder, and a vigorous maize plant can produce 
25 million pollen grains, which is much more than required for pollinating the 500-1000 ovules present in a female flower (cob). The tassel has no role to play after completion of pollination. A small-sized tassel is preferred to reduce the sink competition, particularly when there is high competition for limited assimilates under stressed condition. A negative correlation between tassel size and grain yield under drought was observed in tropical maize populations (Bolaños and Edmeades, 1996). Tassel size is a highly heritable trait and can be easily altered by selection (Fischer et al., 1987). Eight cycles of recurrent selection for mid-season drought tolerance resulted in a reduction of $(-0.45)$ primary tassel branches per plant and tassel biomass $(-2.6 \%)$ per cycle, although the trait was not under direct selection (Bolaños and Edmeades, 1993). In another study, direct selection for reduced tassel branches led to a significant increase in female inflorescence biomass at $50 \%$ silking, a reduction in tassel biomass and an increase in HI (Fischer et al., 1987). These findings indicate that reduced tassel size in tropical maize is directly associated with increase in ear growth at flowering and in $\mathrm{HI}$.

\section{Groundnut}

The segregating populations, derived from crosses involving known drought-tolerant germplasm and widely adapted high-yielding cultivars, are generation-advanced/evaluated under rainfed conditions at ICRISAT, Patancheru, India. The advanced breeding lines are yield tested in both rainy (rainfed conditions at ICRISAT (Patancheru) and Anantapur, India) and post-rainy (simulated mid-season stress conditions at ICRISAT (Patancheru)) seasons in replicated trials. The promising drought-tolerant varieties identified on the basis of their pod and seed yield, after 3 years of evaluation, are included in the international drought trial, tested by cooperators in Asia and Africa. From such evaluation, we identified ICGVs 87354 , 86187 and 86647, which consistently outyielded controls in acute drought-prone areas in India, and ICGV 86635 in Thailand and Indonesia (Reddy et al., 1994). ICGV 87354 has been shown to possess higher T, TE and HI (Rachaputi and Wright, 2003), contributing to its higher performance under water-limiting conditions. Further, simultaneous evaluations for drought tolerance under imposed drought conditions at ICRISAT revealed that ICGSs 11 , 37, 44 and 76, ICG (FDRS) 10 and ICGV 86021 are drought tolerant. The first four varieties were released in India, the fifth in India and Myanmar, and the sixth in Indonesia.

Short-duration, high-yielding groundnut cultivars are required for many agroecological situations in the SAT. Using predetermined cumulative thermal time as a basis to select for earliness (Vasudeva Rao et al., 1992), ICRISAT developed several short-duration varieties, with potential to escape terminal drought; some of these varieties have been released for cultivation in some countries (Fig. 8.9).

New breeding approaches utilizing physiological traits have been proposed to improve the understanding and efficiency of selection of superior drought-tolerant genotypes. Variations for T, TE and HI have been reported in groundnut. More recently, it has been shown that the negative association observed between TE and HI can be broken, thus offering scope to combine TE and $\mathrm{HI}$ in groundnut for improved yield performance. Interestingly, genotypes involving ICGSs 44 and 76 or ICGVs 86754 and 87354 in their pedigrees, all reported to be tolerant to drought, had superior yield performance because of higher TE and $\mathrm{HI}$ or all the three traits, while for the other genotypes, the dominant contribution to the yield was from $\mathrm{T}$ and/or HI (Rachaputi and Wright, 2003). There is therefore scope for pyramiding physiological traits associated with drought tolerance into improved genetic background. Yield performance of some of these selected lines was superior even under irrigated conditions (Nigam et al., 2002), indicating that the physiological traits such as TE and $\mathrm{HI}$ could be used as a selection criterion for high water productivity under irrigated conditions and in high rainfall areas.

The CIDL and SLA have been identified as surrogate traits associated with TE in groundnut. SLA is a crude but easily measurable parameter, and can be used as a rapid and inexpensive selection criterion for high TE. Further, it has been demonstrated that SPAD chlorophyll metre readings (SCMR) serve as a rapid, low-cost and non-destructive technique to screen large breeding populations for SLA 


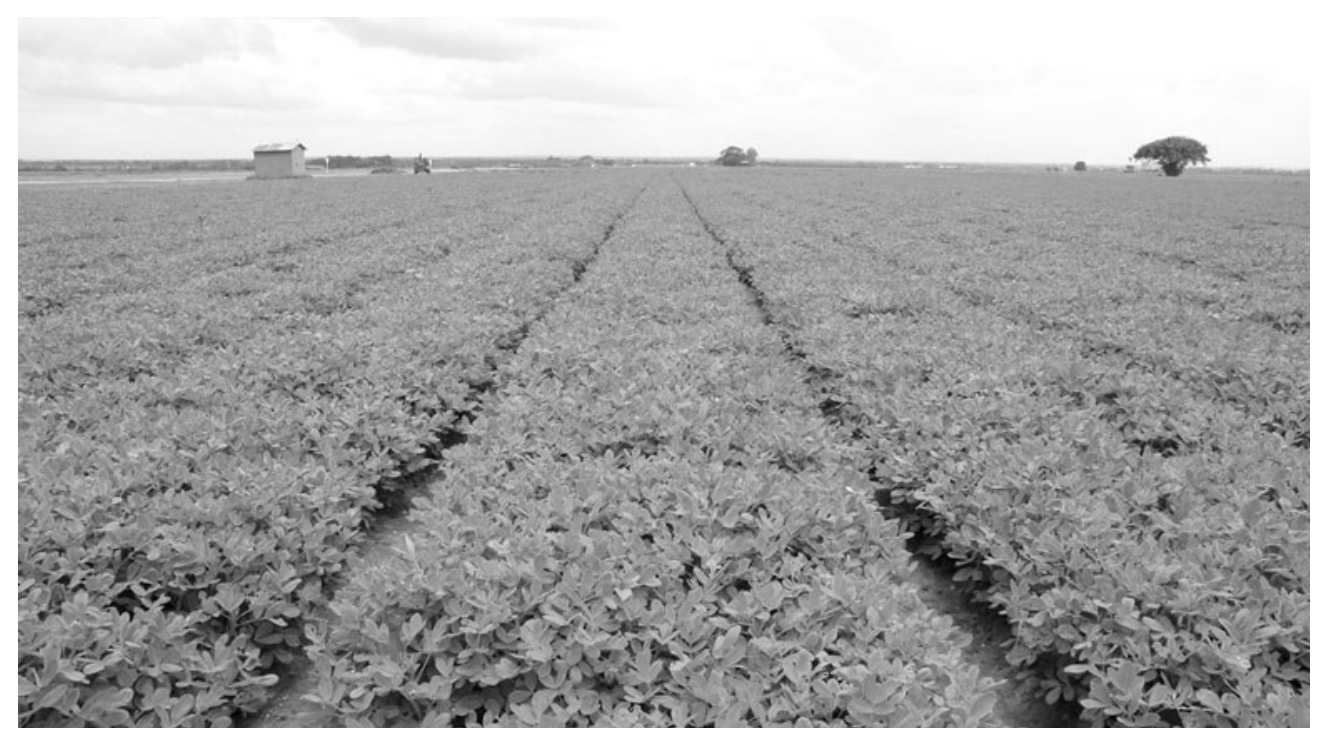

Fig. 8.9. Drought-tolerant groundnut varieties enhance adaptation to varied cropping systems.

(Nageswara Rao et al., 2001) and specific leaf nitrogen (Madhava et al., 2003). Screening of groundnut germplasm for SLA indicated significant variability within and between taxonomic groups of groundnut. Genotypes belonging to the variety hypogaea (Virginia bunch and runner types) had a lower mean SLA than those of variety fastigiata (Valencia and Spanish types), suggesting the likelihood of higher TE. However, the former had lower partitioning ability than the latter. Groundnut genotypes with lower SLA (high TE) have shown more stability in dry matter production under drought (Nigam et al., 2002).

\section{Chickpea}

One way for the chickpea crop to escape endof-season drought is to develop varieties with early growth vigour, early flowering and early maturity (Calcagno and Gallo, 1993). Kumar et al. (1985) developed an extra-early chickpea, ICCV 2, from a transgressive segregant of a cross involving five chickpea lines (Kumar and Abbo, 2001). A major recessive gene, efl-1, responsible for about 3 weeks difference in flowering time has been identified (Kumar and van Rheenen, 2000). A super-early chickpea segregant, ICCV 96029, which flowers about a week earlier than either of the parents, was selected from a cross involving two extra-early varieties (Kumar and Rao, 1996). These earlyflowering genotypes will be useful in combining earliness with other drought-tolerance traits to develop genotypes with stable yields.

\section{Pigeonpea}

\section{Short- and extra-short-duration pigeonpea}

Pigeonpea in India is traditionally grown during the rainy season (180-270 days duration) as an intercrop. However, since the late 1970s it has been shown that genotypes of shorter duration (120-150 days), when grown during the rainy season, can give yields similar to, or even higher than, long-duration genotypes in northern India (Saxena and Yadav, 1975). In Australia, properly managed photoperiod-insensitive genotypes could produce grains up to $8.8 \mathrm{t} / \mathrm{ha}$ (Wallis et al., 1983). The development and release of short-duration pigeonpea varieties that mature in about 120 days has helped the expansion of the crop to newer areas (Singh et al., 1990). These varieties are relatively insensitive to photoperiod and show high per day productivity. 


\section{Pigeonpea hybrids}

The world's first pigeonpea hybrid (ICPH 8), based on genetic male sterility, was released in 1991 for cultivation in India, with $20-34 \%$ yield advantage (Saxena, 2002). ICPH 8 also showed drought, disease and waterlogging tolerance (Saxena et al., 1996). Further, using shortduration male sterile lines (Reddy et al., 1995), the Indian programme released five short-duration hybrids (COPH 1, COPH 2, PPH, AKPH 2022 and AKPH 4104), with $11-64 \%$ yield advantage over the controls (Saxena, 2002). These hybrids have revealed a higher seedling vigour, crop growth rate and pod/seed density, and higher plasticity with no yield reduction at suboptimal population levels compared with controls (Fig. 8.10) (Saxena et al., 1992).

\section{Enhancing Drought Tolerance Using Biotechnological Tools}

\section{Introgression breeding using wild relatives}

Wild relatives of groundnut, chickpea and pigeonpea are endowed with important traits necessary for the improvement of the three legumes: Arachis glabrata, Arachis cardenasii and Arachis pintoi in groundnut with multiple resistance to drought, diseases and insects
(Fisher and Cruz, 1994); Cicer stapfianum, Cicer subaphyllum and Cicer pungens in chickpea with drought tolerance and deep root system (van der Maesen, the Netherlands, personal communication); and Cajanus acutifolius and Cajanus confertiflorus in pigeonpea with silvery hairs, which confer drought tolerance (van der Maesen, 1986). Some of the above wild species are cross compatible with their respective cultigens, and work is in progress at ICRISAT to introgress droughttolerance traits into improved genetic background in these legumes. An interspecific derivative in chickpea, BG 1103 (renamed as Pusa 1103), has been released for cultivation in northern India because of its high yield and tolerance to fusarium wilt and drought (Abbo et al., 2007).

\section{Marker-aided introgression of QTL associated with drought tolerance}

\section{Pearl millet}

Linkage groups (LG) 2, 4 and 6 are reported to harbour several QTLs associated with drought tolerance, flowering, stover and grain yield, panicle numbers, $\mathrm{HI}$, and panicle $\mathrm{HI}$, with some common QTL across stress environments and tester backgrounds (Yadav et al., 2002, 2003,

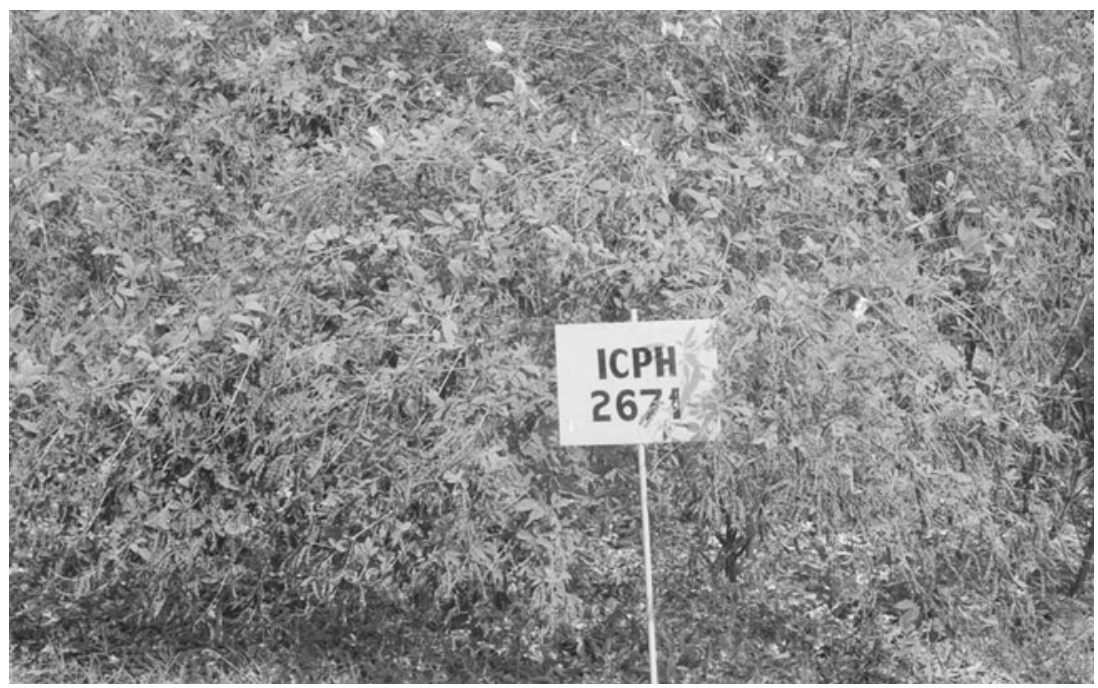

Fig. 8.10. Hybrid pigeonpea cultivars have shown better drought tolerance. 
2004). Bidinger et al. (2005) demonstrated that QTL-based hybrids outyielded under stress but with yield penalty under non-stress environments. More recently, Bidinger et al. (2007) identified three QTLs as primary candidates for marker-assisted selection (MAS) for improved grain yield across variable post-flowering moisture environments. The QTLs on LG2 and LG3 also co-mapped with QTLs for HI across environments for grain numbers and individual grain mass under severe terminal stress. Neither had a significant QTL $\times$ environment interaction, indicating their predictive effects should occur across a broad range of available moisture environments. ICRISAT has initiated a large-scale marker-aided breeding programme to enhance post-flowering drought tolerance in pearl millet.

\section{Sorghum}

An integrated, interactive sorghum linkage map based on all available published information, incorporating RFLP (restriction fragment length polymorphism) and SSR (simple sequence repeat) marker locus positions as well as approximate map positions of stay-green QTLs, has been developed and made available globally (www.icrisat.org). Post-flowering drought in sorghum is associated with the stay-green phenotype. Xu et al. (2000) reported several QTLs with large effects for stay-green and chlorophyll content under post-flowering droughtstress environments; few QTLs for stay-green coincided with the chlorophyll content QTL. Some of the sorghum stay-green QTLs also corresponded with stay-green QTLs in maize and were congruent with other drought-related traits in maize and rice (Kebede et al., 2001). More recently, Harris et al. (2007) demonstrated that some of the sorghum stay-green QTLs individually reduced post-flowering drought-induced leaf senescence when near-isogenic lines (NIL) containing individual QTLs were evaluated under drought-stress environments. ICRISAT initiated marker-assisted backcross to transfer stay-green QTLs with major effects from staygreen donors (B35 and E 36-1) into a range of diverse genotypes from Asia, Africa and Latin America (Fig. 8.11). Thus there is now an opportunity to assess the efficacy of marker-assisted backcrossing for this trait, which can be scored

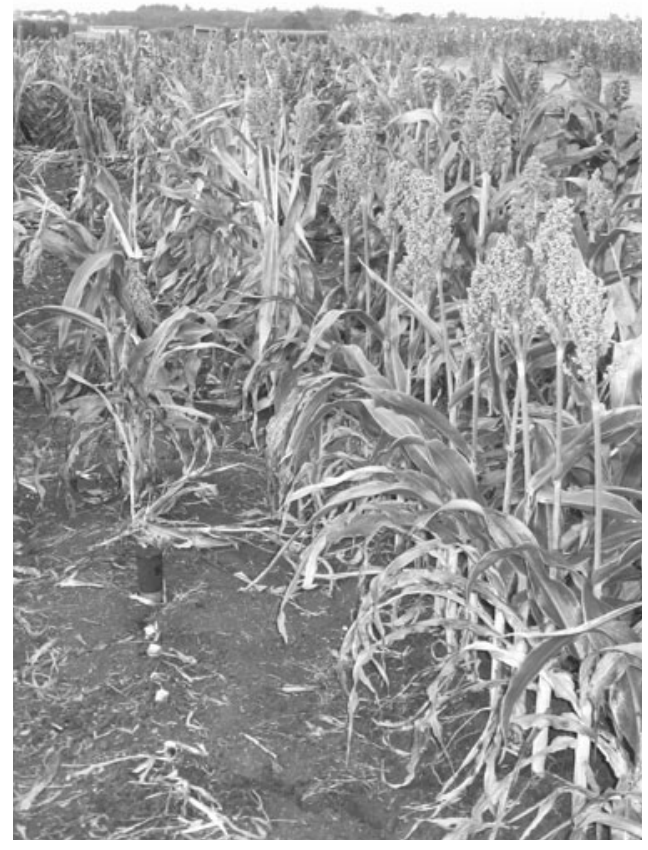

Fig. 8.11. Expression of stay-green trait (in sorghum) under receding soil moisture conditions in a vertisol.

phenotypically only under conditions of terminal drought stress.

\section{Maize}

Large numbers of QTLs associated with grain yield, yield components, and for secondary traits such as ears per plant, ASI and leaf abscisic acid concentration (L-ABA) have been reported in maize under different water regimes including severe drought stress. QTLs for leaf growth co-localized with QTLs for ASI (Welcker et al., 2007). QTLs for seminal root growth colocalized with QTLs for grain yield and drought tolerance index (Tuberosa et al., 2002). Giuliani et al. (2005) field evaluated near-isogenic hybrids containing a major QTL for L-ABA for 2 years under well-watered and water-stressed conditions. They reported that the QTL allele for high L-ABA markedly reduced stomatal conductance and root lodging. Across water regimes, the QTL confirmed its effect on L-ABA and showed a concurrent effect on root angle, branching, number, diameter and dry weight. This QTL affects root lodging through a constitutive effect on root architecture. Landi et al. 
(2005) validated a major QTL for L-ABA that affects root traits and relative water content. Tuberosa et al. (2003) reported several chromosome regions affecting root traits and grain yield under well-watered and/or droughtstressed conditions, with most important QTL effects on few chromosome bins. Two QTLs with major effects on yield and stay-green under post-flowering drought had pleotropic effects on yield under non-stressed conditions (Sari-Gorla et al., 1999).

More recently, Ribaut and Ragot (2007) demonstrated that introgression of favourable alleles at five target regions, involved in the expression of yield components and flowering traits, increased grain yield and reduced the asynchrony between male and female flowering under water-limited conditions. They recovered $85 \%$ of the recurrent parent's genotype at nontarget loci only in four generations of markerassisted backcrossing (MABC) by screening large segregating populations for three of the four generations. Mean grain yield of MABC-derived hybrids was consistently higher than that of control hybrids under severe water stress. Under those conditions, the best five MABC-hybrids yielded, on average, at least $50 \%$ more than the control hybrids. However, under mild stress, defined as resulting in $<50 \%$ yield reduction, no difference was observed between MABC-derived hybrids and the control hybrids, confirming that genetic regulation for drought tolerance is dependent on stress intensity.

\section{Groundnut}

Krishnamurthy et al. (2007) evaluated TE in a set of 318 RILs, derived from a cross between a high TE (ICGV 86031) and a low TE (TAG24) parent, using SLA, SCMR and carbon isotope discrimination $\left(\delta^{13}\right)$ as surrogate of TE under progressive soil drying in a pot culture. Large and consistent variation exists for $\mathrm{TE}$ in this population; however, surrogate traits turned out to relate little $(r<0.13-0.15)$ with TE. New sources of drought tolerance have been identified, which need to be further assessed for drought-tolerance traits. A new set of SSR markers has been generated, which is currently being assessed to identify genetically diverse, drought-tolerant parents for developing new mapping populations.

\section{Chickpea}

Research efforts have been made at ICRISAT to characterize and map QTLs associated with drought-avoidance root traits. RILs involving ICC 4958 (a genotype with large roots) and Annigeri, when evaluated under terminal drought conditions, showed large variations for rooting depth and root biomass at 35 days after sowing, shoot biomass and seed yield at maturity, and partitioning. However, no direct relationship between seed yield and root depth or root biomass could be established from this study, probably owing to moderate drought intensity observed during the crop season. The root-trait benefits on the yield were clearly shown to be visible in environments with a productivity level of $<1.0 \mathrm{t} / \mathrm{ha}$ (Saxena, 1987).

New sources of genetic variation, ICCs 1431, 8350, 15697, 3512 and 11498, with deep root traits and drought tolerance have been identified (Kashiwagi et al., 2005). New mapping populations involving ICC 8261 and ICC 4958 (large root) with ICC 283 and ICC 1882 (small root) have been developed, and the $\mathrm{F}_{1}, \mathrm{~F}_{2}, \mathrm{BC}_{1}$ and $\mathrm{BC}_{2}$ populations are being analysed for the estimation of genetic components and evaluated for root traits and field agronomic performance. A large number of SSR markers are now available to genotype these populations using ABI3700 at ICRISAT. A major QTL contributing to one-third of variation for root length and root biomass has been identified (Chandra et al., 2004).

\section{Association mapping}

Conventional linkage mapping for identification of trait markers relies on the development of defined genetic populations: NILs, RILs and advanced backcross derivatives. The development of such populations takes several years and is expensive, and the resultant markers must be validated in diverse populations before application in breeding programmes. Therefore, there has been considerable interest in the development of methodologies that do not require the creation of mapping populations and generate markers that can be more immediately applied in diverse breeding programmes. Linkage disequilibrium analysis is an alternative means of 
identifying a close association between trait (such as drought tolerance) and marker loci. It relies on population-level associations among alleles at trait loci and those at nearby markers. Such associations typically arise when all or most of the trait alleles in a population share a common ancestral origin. This approach is based on the use of natural populations rather than genetic populations, which has the added advantage that the resultant marker tends to be both genetically and physically close to the gene of interest and, therefore, more readily applied in a diverse range of breeding programmes. Marker-trait association using this approach has been established in crop plants (Dwivedi et al., 2007b). However, this approach has its own limitation with respect to population structure, which needs to be taken care of to avoid false discovery.

\section{Transgenic}

\section{Maize}

AtNF-YB1, a transcription factor from the nuclear factor Y (NF-Y) family, confers improved performance in Arabidopsis under drought conditions. Nelson et al. (2007) identified maize homologues (ZmNF-YB2) of AtNF-YB1, which they used to transform inbred elite maize. The transgenic maize plants constitutively expressing ZmNF-YB2 showed less leaf rolling, cooler leaf temperature and a higher chlorophyll index, photosynthetic rate and stomatal conductance; all these stressadaptive traits contributed to grain yield advantage under water-limited environments. The best-performing transgenic lines produced about $50 \%$ increase in grain yield relative to the irrigated control. Qin et al. (2007) isolated $Z m D R E B 2 A$, a DREB2 homologue from maize, which is induced in response to cold, drought, salt and heat stresses in seedlings. Maize transgenic lines with $Z m D R E B 2 A$ improved drought and heat-stress tolerance, which could be due to induction of late embryogenesis abundant protein (LEA), heat shock and detoxification genes.

Glycine betaine plays an important role in confering abiotic stress tolerance in some plants including maize. Quan et al. (2004) transformed a maize inbred line with the beta gene from Escherichia coli encoding choline dehydro- genase, a key enzyme in the biosynthesis of glycine betaine from choline. The transgenic plants accumulated higher levels of glycine betaine, were more tolerant to drought, and produced significantly higher grain yield than wild-type plants after drought treatment. The enhanced glycine betaine accumulation in transgenic plants provides greater protection of the integrity of the cell membrane and greater activity of enzymes compared with wild-type plants under drought stress.

\section{Groundnut}

Water use efficiency under drought conditions is one of the promising traits to improve and stabilize crop yields under drought conditions. The recent work at ICRISAT revealed that when a popular groundnut cultivar, JL 24, was introduced with DREB1A from Arabidopsis (through Agrobacterium tumefaciens), driven by the stress-inducible promoter $r d 29 \mathrm{~A}$, the transgenic plants did not show growth retardation. When T3 progenies were exposed to progressive soil drying in a pot-culture experiment, all the transgenic plants were able to maintain a transpiration rate equivalent to the well-watered control in soil dry enough to reduce the transpiration rate in wild-type $\mathrm{JL} 24$, with most of these plants achieving higher TE. One of the plants under water-limited conditions showed $40 \%$ higher TE than the wild-type JL 24 (Bhatnagar-Mathur et al., 2007). Vadez et al. (2007) reported that DREB1A seems to be involved in the development of groundnut roots under drought conditions, as they noted excessive root growth in transgenic plants whereas roots remained unchanged in wildtype JL 24, which resulted in higher water uptake from the soil.

\section{Conclusion}

Globally, the five ICRISAT crops and rainfed maize play a predominant role in enhancing the rural livelihood opportunities in arid and semiarid regions, which experience acute water shortage. A combination of approaches has been employed to enhance the adaptation of these crops under drought conditions. These include matching the genotypes to the environment, 
developing short-duration varieties, selecting for stable yield and wide adaptability, screening and breeding under water-limiting environments and/or imposed stress conditions, and employing cultivar options (varieties versus hybrids). However, these approaches have resulted in moderate success in breeding cultivars that have given enhanced water productivity under drought conditions.

Recently, a more focused research on drought has enabled researchers to identify simple and effective traits associated with drought tolerance. For example, panicle $\mathrm{HI}$ and individual grain mass in pearl millet; glossy and stay-green in sorghum; deep root in chickpea; T, TE and HI in groundnut; and ASI, ears per plant, leaf senescence and tassel size in maize. Using these approaches, several genetically enhanced products have been developed, some of which have reached the farmers' fields.

Recent advances in genome mapping have enabled researchers to apply DNA markers technology to dissect the genetic structure of the germplasm collection, identify QTLs associated with drought-tolerance traits, and apply MAS in combination with conventional breeding to enhance drought tolerance in these crops. Products of MAS in pearl millet and maize have conclusively shown superior performance under severe drought-stress conditions, but no advantage under mild drought stress or under wellwatered conditions. Genetically transformed groundnut with the DREB1A gene driven by the stress-inducible promoter $\mathrm{rd} 29 \mathrm{~A}$ has shown promise in enhancing drought tolerance, with no symptoms of growth retardation. Transgenic maize containing ZmNF-YB2 or ZmDREB2A has contributed to enhanced drought tolerance and/or grain yield advantage under droughtstress conditions. A combination of approaches (trait-based selection, QTLs and transgene) needs to be deployed to support the empirical approach in order to enhance drought tolerance in these crops.

\section{References}

Abbo, S., Redden, R.J. and Yadav, S.S. (2007) Utilization of wild relatives. In: Yadav, S.S., Redden, R.J., Chen, W. and Sharma, B. (eds) Chickpea Breeding and Management. CAB International, Wallingford, UK, pp. 338-368.

Acevedo, E. and Ferreres, E. (1993) Resistances to abiotic stresses. In: Hayward, M.D., Bosemark, N.O. and Romagosa, I. (eds) Plant Breeding: Principles and Prospects. Chapman and Hall, London, UK, pp. $406-421$.

Banziger, M., Betran, F.J. and Lafitte, H.R. (1997) Efficiency of high nitrogen selection environments for improving maize for low nitrogen target environment. Crop Science 37, 1103-1109.

Banziger, M., Edmeades, G.O., Beck, D. and Bellon, M. (2000a) Breeding for drought and nitrogen stress tolerance in maize. From theory to practice. CIMMYT, Mexico.

Banziger, M., Mugo, S. and Edmeades, G.O. (2000b) Breeding for drought tolerance in tropical maize conventional approaches and challenges to molecular approaches. In: Ribaut, J.M. and Poland, D. (eds) Molecular Approaches for the Genetic Improvement of Cereals for Stable Production in Water-limited Environments. CIMMYT, El Batan, Mexico, pp. 69-72.

Banziger, M., Pixley, K.V., Vivek, B. and Zambezi, B.T. (2000c) Characterization of elite maize germplasm grown in eastern and southern Africa: results of the 1999 regional trials conducted by CIMMYT and the Maize and Wheat Improvement Research Network for SADC. CIMMYT, Harare, Zimbabwe, pp. 1-44.

Bekavac, G., Stojakovic, M., Jockovic, D., Bocanski, J. and Purar, B. (1998) Path analysis of stay-green trait in maize. Cereal Research Communications 26, 161-167.

Bhatnagar-Mathur, P., Devi, M.J., Reddy, D.S., Lavanya, M., Vadez, V., Serraj, R., Yamaguchi-Shinozaki, K. and Sharma, K.K. (2007) Stress-inducible expression of At DREB1A in transgenic groundnut (Arachis hypogaea L.) increases transpiration efficiency under water limiting conditions. Plant Cell Reports 26, 2071-2082.

Bidinger, F.R. and Mukuru, S.Z. (1995) Threshing percentage as an indicator of terminal drought stress in sorghum. In: Mukuru, S.Z. and King, S.B. (eds) Eighth EARSAM Regional Workshop on Sorghum and Millets, 30 Oct-5 Nov 1992, Wad Medani, Sudan. International Crops Research Institute for the SemiArid Tropics (ICRISAT), Patancheru, India, pp. 27-35. 
Bidinger, F.R., Mahalakshmi, V., Talukdar, B.S. and Alagarswamy, G. (1982) Improvement of drought resistance in pearl millet. In: Drought Resistance in Crops with Emphasis on Rice. International Rice Research Institute (IRRI), Los Baños, Philippines. pp. 357-375.

Bidinger, F.R., Mahalakshmi, V. and Rao, G.D.P. (1987a) Assessment of drought resistance in pearl millet (Pennisetum americanum (L.) Leeke). I. Factors affecting yields under stress. Australian Journal of Agricultural Research 38, 37-48.

Bidinger, F.R., Mahalakshmi, V. and Rao, G.D.P. (1987b) Assessment of drought resistance in pearl millet (Pennisetum americanum (L.) Leeke). II. Estimation of genotype response to stress. Australian Journal of Agricultural Research 38(1), 49-59.

Bidinger, F.R., Hammer, G.L. and Muchow, R.C. (1996) The physiological basis of genotype by environment interaction in crop adaptation. In: Cooper, M. and Hammer, G.L. (eds) Plant Adaptation and Crop Improvement. CAB International, Wallingford, UK, pp. 329-347.

Bidinger, F.R., Chandra, S. and Mahalakshmi, V. (2000) Genetic improvement of tolerance to terminal drought stress in pearl millet (Pennisetum glaucum (L) R. Br.) In: Ribaut, J.M. and Poland, D. (eds) Molecular Approaches for the Genetic Improvement of Cereals for Stable Production in Water-limited Environments. CIMMYT, El Batan, Mexico, pp. 59-63.

Bidinger, F.R., Serraj, R., Rizvi, S.M.H., Howarth, C.J., Yadav, R.S. and Hash, C.T. (2005) Field evaluation of drought tolerance QTL effects on phenotype and adaptation in pearl millet (Pennisetum glaucum (L.) R. Br.) topcross hybrids. Field Crops Research 94, 14-32.

Bidinger, F.R., Napolean, T., Hash, C.T., Yadav, R.S. and Howarth, C.J. (2007) Quantitative trait loci for grain yield in pearl millet under variable post-flowering moisture conditions. Crop Science 47, 969-980.

Bieler, P., Fussel, L.K. and Bidinger, F.R. (1993) Grain growth of Pennisetum glaucum (L.) R. Br. under wellwatered and drought-stressed conditions. Field Crops Research 31, 41-54.

Blum, A., Jordan, W.R. and Arkin, G.F. (1977) Sorghum root morphogenesis and growth. II. Manifestation of heterosis. Crop Science 17, 153-157.

Bolaños, J. and Edmeades, G.O. (1993) Eight cycles of selection for drought tolerance in lowland tropical maize. II. Responses in reproductive behaviour. Field Crops Research 31, 253-268.

Bolaños, J. and Edmeades, G.O. (1996) The importance of the anthesis-silking interval in breeding for drought tolerance in tropical maize. Field Crops Research 48, 65-80.

Bolaños, J., Edmeades, G.O. and Martinez, L. (1993) Eight cycles of selection for drought tolerance in lowland tropical maize. III. Response in drought-adaptive physiological and morphological traits. Field Crops Research 31, 269-286.

Boote, K.J., Varnell, R.J. and Duncan, W.G. (1976) Relationships of size, osmotic concentration, and sugar concentration of groundnut pods to soil water. Proceedings of Crop and Soil Science Society, Florida 35 , 47-50.

Boote, K.J., Stansell, J.R., Schubert, A.M. and Stone, J.T. (1982) Irrigation, water use, and water relations. In: Pattee, H.E. and Young, C.T. (eds) Peanut Science and Technology. American Peanut Research Education Society, Yoakum, Texas, USA, pp. 164-205.

Borrell, A.K. and Douglas, A.C.L. (1996) Maintaining green leaf area in grain sorghum increases yield in a water-limited environment. Third Australian Sorghum Conference, Tamworth, Melbourne. Occasional Publication No. 93, pp. 315-322.

Bruce, W.B., Edmeades, G.O. and Baker, T.C. (2002) Molecular and physiological approach to maize improvement for drought tolerance. Journal of Experimental Botany 53, 13-25.

Byrne, P.F., Bolaños, J., Edmeades, G.O. and Eaton, D.L. (1995) Gains from selection under drought versus multilocation testing in related tropical maize populations. Crop Science 35, 63-69.

Calcagno, F. and Gallo, G. (1993) Physiological and morphological basis of abiotic stress resistance in chickpea. In: Singh, K.B. and Saxena, M.C. (eds) Breeding for Stress Tolerance in Cool Season Food Legumes. John Wiley \& Sons and Sayce Publishing, London, pp. 293-309.

Castleberry, R.M., Crum, C.W. and Krull, C.F. (1984) Genetic improvements of US maize cultivars under varying fertility and climatic environments. Crop Science 24, 33-36.

Chandra, S., Buhariwalla, H.K., Kashiwagi, J., Harikrishna, S., Sridevi, K.R., Krishnamurthy, L., Serraj, R. and Crouch, J.H. (2004) Identifying QTL-linked markers in marker-deficient crops. In: Proceedings of Fourth International Crop Science Congress, Brisbane, Australia. http://www.cropscience.org.au/icsc2004/ poster/3/4/1/795_chandras.htm

Chapman, S.C., Cooper, M., Hammer, G.L. and Butler, D.G. (2000) Genotype by environment interactions affecting grain sorghum. II. Frequencies of different seasonal patterns of drought stress are related to location effects on hybrid yields. Australian Journal of Agricultural Research 51, 209-221. 
Chauhan, Y.S., Saxena, N.P. and Johansen, C. (1992) Abiotic factors limiting chickpea and pigeonpea production. In: Sachan, J.N. (ed.) Proceedings of National Symposium on New Frontiers in Pulses Research and Development. Directorate of Pulses Research, Kanpur, India, pp. 111-123.

Chauhan, Y.S., Johansen, C. and Singh, L. (1993) Adaptation of extra short duration pigeonpea to rainfed semi-arid envirionments. Experimental Agriculture 29, 233-243.

Chauhan, Y.S., Silim, S.N., Rao, J. and Johansen, C. (1997) A pot technique to screen pigeonpea cultivars for resistance to waterlogging. Journal of Agronomy and Crop Science 178, 179-183.

Chauhan, Y.S., Wallace, D.H., Johansen, C. and Singh, L. (1998) Genotype by environment interaction effect on yield and its physiological basis in short duration pigeonpea. Field Crops Research 59, 141-150.

Choi, K.J., Chin, M.S., Park, K.Y., Lee, H.S., Seo, J.H. and Song, D.Y. (1995) Heterosis and heritability of staygreen characters. Maize Genetics Cooperative Newsletter 69, 122-123.

Cooper, M. and DeLacy, I.H. (1994) Relationships among analytical methods used to study genotypic variation and genotype by environment interaction in plant breeding multi-environment experiments. Theoretical and Applied Genetics 88, 561-572.

Duvick, D.N. (1995) Biodiversity, carrying capacity and people. In: Annual Meeting. American Association for Advancement in Science, Atlanta, Georgia, USA.

Dwivedi, S.L., Bertioli, D.J., Crouch, J.H., Valls, J.E., Upadhyaya, H.D., Fávero, A., Moretzsohn, M. and Paterson, A. (2007a) Peanut. In: Kole, C. (ed.) Genome Mapping and Molecular Breeding in Plants, Vol. 2. Springer-Verlag, Berlin, Germany, pp. 115-151.

Dwivedi, S.L., Crouch, J.H., Mackill, D.J., Xu, Y., Blair, M.W., Ragot, M., Upadhyaya, H.D. and Ortiz. R. (2007b) The molecularization of public sector crop breeding: progress, problems, and prospects. Advances in Agronomy 95, 163-318.

Edmeades, G.O., Chapman, S.C. and Lafitte, H.R. (1994) Photoperiod sensitivity of tropical maize cultivars is reduced by cool night temperatures. Presented at the 86th Annual Meeting of the American Society of Agronomy, Seattle. USA.

Edmeades, G.O., Banziger, M., Chapman, S.C., Ribaut, J.M. and Bolaños, J. (1995) Recent advances in breeding for drought tolerance in maize. Presented at the West and Central Africa Regional Maize and Cassava Workshop, Cotonou, Republic of Benin.

Edmeades, G.O., Bolaños, J., Banziger, M., Ribaut, J.M., White, J.W., Reynolds, M.P. and Lafitte, H.R. (1998) Improving crop yields under water deficits in the tropics. In: Chopra, V.L., Singh, R.B. and Varma, A. (eds) Crop Productivity and Sustainability - Shaping the Future. Proceedings of 2nd International Crop Science Congress, Oxford and IBH, New Delhi, India, pp. 437-451.

Edmeades, G.O., Bolaños, J., Elings, A., Ribaut, J.M., Banziger, M. and Westgate, M.E. (2000) The role and regulation of the anthesis-silking interval in maize. In: Westgate, M.E. and Boote, K.J. (eds) Physiology and Modeling Kernel Set in Maize. CSSA Special Publication No. 29. Madison, Wisconsin, USA, pp. 43-73.

Fischer, K.S., Edmeades, G.O. and Johnson, E.C. (1987) Recurrent selection for reduced tassel branches number and reduced leaf area density above the ear in tropical maize populations. Crop Science 27, 1150-1156.

Fisher, M.J. and Cruz, P. (1994) Some ecophysiological aspects of Arachis pintoi. In: Kerridge, P.C. and Hardy, B. (eds) Biology and Agronomy of Forage Arachis. CIAT, Cali, Columbia, pp. 53-70.

Fisher, R.A. and Maurer, R. (1978) Drought resistance in spring wheat cultivars. 1. Grain yield response. Australian Journal of Agricultural Research 29, 897-912.

Fussell, L.K., Craig, J., Pearson, J. and Norman, M.J.T. (1980) Effect of temperature during various growth stages on grain development and yield of Pennisetum americanum. Journal of Experimental Botany 31, 621-633.

Fussell, L.K., Bidinger, F.R. and Bieler, P. (1991) Crop physiology and breeding for drought tolerance: research and development. Field Crops Research 27, 183-199.

Gibbons, R.W. (1978) Adaptation and utilization of groundnuts in different environments and farming systems. In: Summerfield, R.J. and Bunting, H. (eds) Advances in Legume Sciences. Royal Botanical Gardens, Kew, UK, pp. 483-493.

Giuliani, S., Sanguineti, M.C., Tuberosa, R., Bellotti, M., Salvi, S. and Landi, P. (2005) Root-ABA1, a major constitutive QTL, affects maize root architecture and leaf $A B A$ concentration at different water regimes. Journal of Experimental Botany 56, 3061-3070.

Gupta, S.C., Johansen, C. and Singh, L. (1989) Uniformity of nomenclature in short duration pigeonpeas. International Pigeonpea News 10, 3-6.

Hammer, G.L. and Muchow, R.C. (1994) Assessing climatic risk to sorghum production in water-limited subtropical environments. 1. Development and testing of a simulation model. Field Crops Research 36, 221-234. 
Hanks, R.J., Keller, J., Rasmussen, V.P. and Wilson, G.D. (1976). Line-source sprinkler for continuous variable irrigation crops production studies. Soil Science Society of America Journal 40, 426-429.

Harris, D., Mathews, R.B., Nageswara Rao, R.C. and Williams, J.H. (1988) The physiological basis for yield differences between four groundnut genotypes in response to drought. III. Developmental processes. Experimental Agriculture 24, 215-226.

Harris, K., Subudhi, P.K., Borrell, A., Jordan, D., Rosenow, D., Nguyen, H., Klein, P., Klein, R. and Mullet, J. (2007) Sorghum stay-green QTL individually reduce post-flowering drought induced leaf senescence. Journal of Experimental Botany 58, 327-338.

Henson, I.E., Mahalakshmi, V., Alagarswamy, G. and Bidinger, F.R. (1984) The effect of flowering on stomatal response to water stress in pearl millet (Pennisetum americanum (L.) Leeke). Journal of Experimental Botany 35, 219-226.

Henzell, R.G., Brengman, R.L., Fletcher, D.S. and McCosker, A.N. (1992) Relationship between yield and non-senescence (stay-green) in some grain sorghum hybrids grown under terminal drought stress. In: Foale, M.A., Henzell, R.G. and Vance, P.N. (eds) Proceedings of 2nd Australian Sorghum Conference, Gatton, Melbourne, Australia. Occasional Publication No. 68. Australian Institute of Agricultural Science, Melbourne, Australia, pp. 355-358.

Henzell, R.G., Hammar, G.I., Borrell, A.K., McIntyre, C.L. and Chapman, S.C. (1997) Research on drought resistance in grain sorghum in Australia. International Sorghum Millets Newsletter 38, 1-8.

House, L.R., Verma, B.N., Ejeta, G., Rana, B.S., Kapran, I., Obilana, A.B. and Reddy, B.V.S. (1997) Developing countries breeding and potential of hybrid breeding. In: Proceedings of International Conference on Genetic Improvement of Sorghum and Pearl Millet, INTSORMIL, Lubbock, Texas, USA; and ICRISAT, India, pp. 84-96.

Hubick, K.T., Shorter, R. and Farquhar, G.D. (1988) Heritability and genotype $\times$ environmental interactions of carbon isotope discrimination and transpiration efficiency in groundnut (Arachis hypogaea L.). Australian Journal of Plant Physiology 15, 799-813.

Hui, J., Wei, X., Xu, Y.L. and Lin, E. (2005) Impacts of climate change on wheat yield in China. Acta Agronomy Sinica 31, 1340-1343.

Johansen, C. (2003) An overview of prospects for genetic enhancement of drought resistance in pigeonpea. In: Saxena, N.P. (ed.) Management of Agricultural Drought: Agronomic and Genetic Options. Oxford \& IBH Publishing Co., New Delhi, India, pp. 143-150.

Johansen, C., Baldev, B., Brouwer, J.B., Erskine, W.B., Jermyn, W.A., Lang, L.J., Malik, B.A., Miah, A.A. and Silim, S.N. (1994) Biotic and abiotic stresses constraining productivity of cool season food legumes in Asia, Africa and Oceania. In: Muehlbauer, F.J. and Kaiser, W.J. (eds) Expanding the Production and Use of Cool Season Food Legumes. Kluwer Academic Publishers, Dordrecht, the Netherlands, pp. 175-194.

Jones, P.G. and Thornton, P.K. (2003) The potential impact of climate change on maize production in Africa and Latin America in 2055. Global Environmental Change 13, 51-59.

Kashiwagi, J., Krishnamurthy, L., Upadhyaya, H.D., Krishna, H., Chandra, S., Vadez, V. and Serraj, R. (2005) Genetic variability for drought-avoidance root traits in the mini core germplasm collection of chickpea (Cicer arietinum L.). Euphytica 146, 213-222.

Kashiwagi, J., Krishnamurthy, L., Singh, S. and Upadhyaya, H.D. (2006) Variation of SPAD chlorophyll meter readings $(\mathrm{SCMR})$ in the mini core germplasm collection of chickpea. Journal of SAT Agricultural Research 2, http://www.icrisat.org/journal/cropimprovement/v2i1/v2i1 variationof.pdf

Kebede, Y. and Menkir, A. (1987) Sorghum improvement for the moisture stress regions of Ethiopia. In: Menyonga, J.N., Bezuneh, T. and Youdeowei, A. (eds) Food Grain Production in Semi-Arid Africa. Proceedings of International Drought Symposium, Nairobi, Kenya, pp. 131-139.

Kebede, H., Subudhi, P.K., Rosenow, D.T. and Nguyen, H.T. (2001) Quantitative trait loci influencing drought tolerance in grain sorghum (Sorghum bicolor L. Moench). Theoretical and Applied Genetics 103, $266-276$.

Ketring, D.L. (1984) Root diversity among groundnut genotypes. Crop Science 24, 229-232.

Krishnamurthy, L., Vadez, V., Devi, M.J., Serraj, R., Nigam, S.N., Sheshshayee, M.S., Chandra, S. and Aruna, R. (2007) Variation in transpiration efficiency and its related traits in a groundnut (Arachis hypogaea L.) mapping population. Field Crops Research 103, 189-197.

Kumar, J. and Abbo, S. (2001) Genetics of flowering time in chickpea and its bearing on productivity in semiarid environments. Advances in Agronomy 72, 107-138.

Kumar, J. and Rao, B.V. (1996) Super-early chickpea developed at ICRISAT Asia Center. International Chickpea and Pigeonpea Newsletter 3, 17-18.

Kumar, J. and van Rheenen, H.A. (2000) A major gene for time of flowering in chickpea. Journal of Heredity $91,67-68$ 
Kumar, J., Haware, M.P. and Smithson, J.B. (1985) Registration of four short duration, fusarium wilt-resistant kabuli (Garbanzo) chickpea germplasms. Crop Science 25, 576-577.

Kumar, J., Sethi, S.C., Johansen, C., Kelley, T.G., Rahman, M.M. and van Rheenen, H.A. (1996). Potential of short-duration chickpea varieties. Indian Journal of Dryland Agricultural Research 11, $28-32$.

Landi, P., Sanguineti, M.C., Salvi, S., Giuliani, S., Bellotti, M., Maccaferri, M., Conti, S. and Tuberosa, R. (2005) Validation and characterization of a major QTL affecting leaf ABA concentration in maize. Molecular Breeding 15, 291-303.

Lopez, F.B., Chauhan, Y.S. and Johansen, C. (1997) Effects of timing of drought stress on leaf area development and canopy light interception of short-duration pigeonpea. Journal of Agronomy and Crop Science 178, $1-7$.

Luo, Q.Y., Bellotti, W., Williams, M. and Bryan, B. (2005) Potential impact of climate change on wheat yields in South Australia. Agricultural Forest Meteorology 132, 273-285.

Madhava, H.B., Sheshshayee, M.S., Shankar, A.G., Prasad, T.G. and Udayakumar, M. (2003) Use of SPAD chlorophyll meter to assess transpiration efficiency of groundnut. In: Cruickshank, A.W., Rachaputi, N.C., Wright, G.C. and Nigam, S.N. (eds) Breeding of Drought-resistant Peanuts. Proceedings of Collaborative Review Meeting, Hyderabad, India. ACIAR Proceedings No. 112. ACIAR, Canberra, Australia, pp. 3-9.

Mahalakshmi, V. and Bidinger, F.R. (1985) Water stress and time of floral initiation in pearl millet. Journal of Agricultural Science, Cambridge 105, 436-445.

Mahalakshmi, V. and Bidinger, F.R. (2002) Evaluation of stay-green sorghum germplasm lines at ICRISAT. Crop Science 42, 965-974.

Mahalakshmi, V., Bidinger, F.R. and Raju, D.S. (1987) Effect of timing deficit on pearl millet (Pennisetum americanum). Field Crops Research 15, 327-339.

Mahalakshmi, V., Bidinger, F.R. and Rao, G.D.P. (1988) Timing and intensity of water deficits during flowering and grain-filling in pearl millet. Agronomy Journal 80, 130-135.

Mahalakshmi, V., Bidinger, F.R. and Rao, G.D.P. (1990) Line-source versus irrigated/non irrigated treatments for evaluation of genotype drought response. Agronomy Journal 82, 841-844.

Mahalakshmi, V., Monyo, E.S., Payne, W., Quattara, S. and Bidinger, F.R. (1997) Breeding pearl millet for drought tolerance. In: Proceedings of International Conference on Genetic Improvement of Sorghum and Pearl Millet. INTSORMIL, Lubbock, Texas, USA; and ICRISAT, India, pp. 443-457.

Maiti, R.K. (1996) Sorghum Science. Science Publishers, Inc., Lebanon, New Hampshire, USA.

Maiti, R.K., Prasada Rao, K.E., Raju, P.S. and House, L.R. (1984) The glossy trait in sorghum. Its characteristics and significance in crop improvement. Field Crops Research 9, 279-289.

Martinez-Barajas, E., Villnueva-Verduzco, C., Molina-Galan, J., Loza-Tavera, H. and Sanchez-de-Jimenez, E. (1992) Relation of rubisco to maize grain improvement: effect of water restriction. Crop Science 32, 718-722.

McCully, M.E. (1999) Roots in soil: unearthing the complexities of roots and their rhizospheres. Annual Review of Plant Physiology and Plant Molecular Biology 50, 695-718.

Nageswara Rao, R.C. and Nigam, S.N. (2003) Genetic options for drought management in groundnut. In: Saxena, N.P. (ed.) Management of Agricultural Drought - Agronomic and Genetic Options. Oxford \& IBH Publishing Co. Pvt. Ltd, New Delhi, India, pp. 123-141.

Nageswara Rao, R.C., Williams, J.H., Sivakumar, M.V.K. and Wadia, K.D.R. (1988) Effect of water deficit at different growth phases of groundnut. II. Response to drought during preflowering phase. Agronomy Journal 80, 431-438.

Nageswara Rao, R.C., Williams, J.H., Wadia, K.D.R., Hubick, K.T. and Farquhar, G.D. (1993) Crop growth, water use-efficiency, and carbon isotope discrimination in groundnut (Arachis hypogaea L.) genotypes under end-of-season drought conditions. Annals of Applied Biology 122, 357-367.

Nageswara Rao, R.C., Talwar, H.S. and Wright, G.C. (2001) Rapid assessment of specific leaf area and leaf nitrogen (Arachis hypogaea L.) using a chlorophyll meter. Journal of Agronomy and Crop Science 186, 175-182.

Nam, N.H., Chauhan, Y.S. and Johansen, C. (1993) Comparison of extra-short duration pigeonpea with shortseason legumes under rainfed condition on Alfisol. Experimental Agriculture 29(3), 307-316.

Nam, N.H., Chauhan, Y.S. and Johansen, C. (2001) Effects of timing of drought stress on growth and grain yield of extra-short duration pigeonpea. Journal of Agricultural Science, Cambridge 136, 179-189.

Nelson, D.E., Repetti, P.P., Adams, T.R., Creelman, R.A., Wu, J., Warner, D.C., Anstrom, D.C., Bensen, R.J., Castiglioni, P.P., Donnarummo, M.G., Hinchey, B.S., Kumimoto, R.W., Maszle, D.R., Canales, R.D., Krolikowski, K.A., Dotson, S.B., Gutterson, N., Ratcliffe, O.J. and Heard, J.E. (2007) Plant nuclear factor $\mathrm{Y}(\mathrm{NF}-\mathrm{Y}) \mathrm{B}$ subunits confer drought tolerance and lead to improved corn yields on water-limited areas. Proceedings of the National Academy of Sciences, USA 104, 16450-16455. 
Nigam, S.N., Nageswara Rao, R.C. and Wright, G.C. (2002) Field screening for drought resistance in groundnut. In: Saxena, N.P. and O'Toole, J.C. (eds) Field Screening for Drought Tolerance in Crop Plants with Emphasis on Rice. Proceedings of International Workshop on Field Screening for Drought Tolerance in Rice. ICRISAT, India and Rockefeller Foundation, New York, pp. 147-151.

Ortiz, R., Ekanayake, I.J., Mahalakshmi, V., Kamara, A., Menkir, A., Nigam, S.N., Singh, B.B. and Saxena, N.P. (2002) In: Yazima, M., Okada, K. and Matsumoto, L. (eds) Water for Sustainable Agriculture in Developing Regions - More Crop for Every Scarce Drop. Proceedings of 8th JIRCAS International Symposium, Tsukuba, Japan. Series No. 10, pp. 11-21.

Osmanzai, M. (1994) Relative performance of sorghum hybrids and open pollinated cultivars under two soil moisture regimes. International Sorghum and Millets Newsletter 35, 131.

Pallas, J.R. Jr, Stansell, J.R. and Koske, T.J. (1979) Effects of drought on Florunner groundnuts. Agronomy Journal 71, 853-858.

Passioura, J.B. (1977) Grain yield, harvest index and water use of wheat. Journal of Australian Institute of Agricultural Science 43, 117-120.

Peng, S., Huang, J., Sheehy, J.E., Laza, R.C., Visperas, R.M., Zhong, X., Centeno, G.S., Khush, G.S. and Cassman, K.G. (2004) Rice yields decline with higher night temperature from global warming. Proceedings of the National Academy of Sciences, USA 101, 9971-9975.

Prabowo, A., Prastowo, B. and Wright, G.C. (1990). Growth, yield and soil water extraction of irrigated and dryland groundnuts in South Sulawesi, Indonesia. Irrigation Science 11, 63-68.

Qin, F., Kakimoto, M., Sakuma, Y., Maruyama, K., Osakabe, Y., PhanTran, L.S., Shinozaki, K. and YamaguchiShinozaki, K. (2007) Regulation and functional analysis of ZmDREB2A in response to drought and heat stresses in Zea mays L. Plant Journal 50, 54-69.

Quan, R., Shang, M., Zhang, H., Zhao, Y. and Zhang, J. (2004) Engineering of enhanced glycine betaine synthesis improves drought tolerance in maize. Plant Biotechnology Journal 2, 477-486.

Rachaputi, N.C. and Wright, G.C. (2003) The physiological basis for selection of groundnut genotypes as parents in breeding for improved drought resistance. In: Cruickshank, A.W., Rachaputi, N.C., Wright, G.C. and Nigam, S.N. (eds) Breeding of Drought-resistant Peanuts. Proceedings of Collaborative Review Meeting, Hyderabad, India. ACIAR Proceedings No. 112. ACIAR, Canberra, Australia, pp. 10-14.

Rana, B.S., Swarnalata, K. and Rao, M.H. (1997) Impact of Genetic Improvement on Sorghum Productivity in India. Proceedings of International Conference on Genetic Improvement of Sorghum and Pearl Millet. INTSORMIL, Lubbock, Texas, USA; and ICRISAT, India, pp. 142-165.

Reddy, B.V.S. (1986) Genetic improvement for drought resistance in sorghum: a plant breeder's view point. In: Genetic Improvement of Drought Resistance. Proceedings of Discussion Series of the Drought Research Seminar Forums, pp. 28-32.

Reddy, L.J., Nigam, S.N. and Nageswara Rao, R.C. (1994) Progress in breeding for drought tolerant groundnut varieties at ICRISAT Center. In: Prasad, M.V.R., Kalpana Sastry, R., Raghavaiah, C.V. and Damodaram, T. (eds) Sustainability in Oilseeds. Indian Society of Oilseeds Research, Hyderabad, India, pp. 131-133.

Reddy, L.J., Saxena, K.B., Sharma, D., Green, J.M., Rao, A.N. and Kumar, R.V. (1995) Registration of ICPM 93006, ICPM 93007, and ICPM 93009, three short-duration genetic male-sterile parental lines of pigeonpea. Crop Science 35, 1715.

Ribaut, J.M. and Ragot, M. (2007) Marker-assisted selection to improve drought adaptation in maize: the backcross approach, perspectives, limitations, and alternatives. Journal of Experimental Botany 58, $351-360$.

Robertson, M.J., Carberry, P.S., Chauhan, Y.S., Ranganathan, R. and Leary, G.J.O. (2001) Predicting growth and development of pigeonpea: a simulation model. Field Crops Research 71, 195-210.

Rosenow, D.T., Quisenberry, J.E., Wendt, C.W. and Clark, L.E. (1983) Drought tolerant sorghum and cotton germplasm. In: Stone, J.F. and Willis, W.O. (eds) Plant Production and Management under Drought Conditions. Elsevier Science Publishers, Amsterdam, the Netherlands, pp. 207-222.

Rosielle, A.A. and Hamblin, J. (1981) Theoretical aspects of selection for yield in stress and not-stress environments. Crop Science 21, 943-946.

Rucker, K.S., Kvien, C.K., Holbrook, C.C. and Hook, J.E. (1995) Identification of groundnut genotypes with improved drought avoidance traits. Peanut Science 22, 14-18.

Saeed, M. and Francis, C.A. (1983) Yield stability in relation to maturity in grain sorghum. Crop Science 23, 683.

Saeed, M., Francis, C.A. and Rajewski, J.F. (1984) Maturity effects on genotype $\times$ environment interaction in grain sorghum. Agronomy Journal 76, 55.

Sari-Gorla, M., Krajewski, P., di Fonzo, N., Villa, M. and Frova, C. (1999) Genetic analysis of drought tolerance in maize by molecular markers. II. Plant height and flowering. Theoretical and Applied Genetics 99, 289-295. 
Saxena, K.B. (2002) Prospects for hybrid pigeonpea. In: Subramanian, M. (ed.) Pulses and Oilseeds Production for Sustainable Agriculture. Tamil Nadu Agricultural University, Coimbatore, India, pp. 28-41.

Saxena, K.B., Chauhan, Y.S., Johansen, C. and Singh, L. (1992) Recent developments in hybrid pigeonpea research. In: Proceedings of National Symposium on New Frontiers in Pulses Research. Directorate of Pulse Research, Kanpur, India, pp. 58-69.

Saxena, K.B., Chauhan, Y.S., Singh, L., Kumar, R.V. and Johanson, C. (1996) Research and development of hybrid pigeonpea. Research Bulletin No. 19. International Crops Research Institute for the Semi-Arid Tropics (ICRISAT), Patancheru, India.

Saxena, N.P. (1987) Screening for adaptation to drought: case studies with chickpea and pigeonpea. In: Saxena, N.P. and Johansen, C. (eds) Adaptation of Chickpea and Pigeonpea to Abiotic Stresses. Proceedings of Consultants' Workshop. ICRISAT, Patancheru, India, pp. 63-76.

Saxena, N.P. (2003) Management of drought in chickpea - a holistic approach. In: Saxena, N.P. (ed.) Management of Agricultural Drought - Agronomic and Genetic Options. Oxford \& IBH Publishing Co. Pvt. Ltd, New Delhi, India, pp.103-122.

Saxena, M.C. and Yadav, D.S. (1975) Some agronomic considerations of pigeonpeas and chickpeas. International Workshop on Grain Legumes. International Crops Research Institute for the Semi-Arid Tropics (ICRISAT), Patancheru, India, pp. 31-61.

Saxena, N.P., Krishnamurthy, L. and Johansen, C. (1993) Registration of a drought resistant germplasm. Crop Science 33, 1424.

Schussler, J.R. and Westgate, M.E. (1995) Assimilate flux determines kernel set at low water potential in maize. Crop Science 35, 1074-1080.

Sedgley, R.H., Siddique, K.H.M. and Walton, G.H. (1990) Chickpea ideotypes for Mediterranean environments. In: Chickpea in the Nineties. Proceedings of Second International Workshop on Chickpea Improvement. International Crops Research Institute for the Semi-Arid Tropics (ICRISAT), Patancheru, India, pp. 87-91.

Seetharama, N., Reddy, B.V.S., Peacock, J.M. and Bidinger, F.R. (1982) Sorghum improvement for drought resistance in crops with emphasis on rice. International Rice Research Institute (IRRI), Los Banos, Laguna, Manila, Philippines, pp. 317-338.

Serraj, R., Purcell, L.C. and Sinclair, T.R. (1999) Inhibition of $\mathrm{N}_{2}$ fixation by drought. A review. Journal of Experimental Botany 50, 143-155.

Shaw, R.H. (1976) Water use and requirements of maize - a review. In: Agrometeorology of the Maize (Corn) Crop. World Meteorological Organization No. 481, 119-134.

Sinclair, T.R., Tanner, C.B. and Bennett, J.M. (1984) Water-use efficiency in crop production. BioScience 34, $36-40$.

Singh, L., Gupta, S.C. and Faris, D.G. (1990) Pigeonpea breeding. In: Nene, Y.L., Hall, S.D. and Sheila, V.K. (eds), The Pigeonpea. CAB International, Wallingford, Oxon, UK. pp. 375-399.

Srinivasan, G., Zaidi, P.H., Singh, N.N. and Sanchez, C. (2003) Increasing productivity through genetic improvement for tolerance to drought and excess-moisture stress in maize (Zea mays L.). In: Veng, S., Craswell, E., Fukai, S. and Fisher, K (eds) Water in Agriculture for 21 st Century. ACIAR Proceedings No. 116. ACIAR, Canberra, Australia, pp. 227-239.

Stansell, J.R. and Pallas, J.E. Jr (1985) Yield and quality response of Florunner groundnut to applied drought at several growth stages. Peanut Science 12, 64-70.

Subbarao, G.V., Johansen, C., Slinkard, A.E., Rao, R.C.N., Saxena, N.P. and Chauhan, Y.S. (1995) Strategies for improving drought resistance in grain legumes. Critical Reviews Plant Sciences 14, 469-523.

Tuberosa, R., Salvi, S., Maria, C.S., Pierangelo, L.M.M. and Conti, S. (2002) Mapping QTLs regulating morpho-physiological traits and yield: case studies, shortcomings, and pespectives in drought-stressed maize. Annals of Botany 89, 941-963.

Tuberosa, R., Salvi, S., Sanguineti, M.C., Maccaferri, M., Giuliani, S. and Landi, P. (2003) Searching for quantitative trait loci controlling root traits in maize: a critical appraisal. Plant Soil 255, 35-54.

Vadez, V., Rao, S., Sharma, K.K., Bhatnagar-Mathur, P. and Devi, J.M. (2007) DREB1A allows for more water uptake in groundnut by a large modification in the root/shoot ratio under water deficit. Journal of SAT Agricultural Research 5(1). http://www.icrisat.org/journal/volumes5/groundnut/gn3.pdf

van der Maesen, L.J.G. (1986) Cajanus DC and Atylosia W\&A (Leguminosae). Agricultural University Wageningen Papers 85-4 (1985). Agricultural University, Wageningen, the Netherlands.

van Oosterom, E.J., Jayachandran, R. and Bidinger, F.R. (1996) Diallel analysis of the stay-green trait and its components in sorghum. Crop Science 36, 549-555. 
Vasudeva Rao, M.J., Nigam, S.N. and Huda, A.K.S. (1992) The thermal time concept as a selection criterion for earliness in groundnut. Peanut Science 19, 7-10.

Virmani, S.M. and Singh, P. (1986) Agroclimatology characteristics of the groundnut regions in the semi-arid tropics. In: Agrometeorology of Groundnut. Proceedings of International Symposium. ICRISAT Sahelian Centre, Naimey, Niger and International Crops Research Institute for the Semi-Arid Tropics (ICRISAT), Patancheru, India, pp. 35-46.

Virmani, S.M., Sivakumar, M.V.K. and Sarkar, R.P. (1982) Rainfall probability and tailoring agriculture to match it. In: Symposium on Rainwater and Dryland Agriculture. Indian National Science Academy, New Delhi, India, pp. 27-33.

Wallis, E.S., Byth, D.E., Whiteman, P.C. and Saxena, K.B. (1983) Adaptation of pigeonpea (Cajanus cajan) to mechanised culture. Proceedings of Australian Plant Breeding Conference. Australian Plant Breeding Society, Adelaide, Australia, pp. 142-145.

Welcker, C., Boussuge, B., Bencivenni, C., Ribaut, J.M. and Tardieu, F. (2007) Are source and sink strengths genetically linked in maize plants subjected to water deficit? A QTL study of the responses of leaf growth and of anthesis-silking interval to water deficit. Journal of Experimental Botany 58, 339-349.

Westgate, M.E. and Bassetti, P. (1990) Heat and drought stress in corn: what really happens to the corn plant at pollination? In: Wilkinson, D. (ed.) Proceedings of the 45th Annual Corn and Sorghum Research Conference. ASTA, Washington, USA. pp. 12-28.

Winkel, T. and Do, F. (1992) Caracteres morphologiques et physiologiques de resistance du mil (Pennisetum glaucum (L.) R. Br.) a la secheresse. L' Agronomie Tropicale 46, 339-350.

Wright, G.C. and Nageswara Rao, R.C. (1994) Groundnut water relations. In: Smartt, J.E. (ed.) The Groundnut Crop: a Scientific Basis for Improvement. Chapman \& Hall, London, UK, pp. 281-336.

Wright, G.C., Hubick, K.T. and Farquhar, G.D. (1988) Discrimination in carbon isotopes of leaves correlates with water-use efficiency of field grown groundnut cultivars. Australian Journal of Plant Physiology 15, $815-825$.

Wright, G.C., Hubick, K.T. and Farquhar, G.D. (1991) Physiological analysis of groundnut cultivar response to timing and duration of drought stress. Australian Journal of Agricultural Research 42, 453-470.

Wright, G.C., Nageswara Rao, R.C. and Farquhar, G.D. (1994) Water use efficiency and carbon isotope discrimination in groundnut under water deficit conditions. Crop Science 34, 92-97.

Xu, W.W., Subudhi, P.K., Crasta, O.R., Rosenow, D.T., Mullet, J.E. and Nguyen, H.T. (2000) Molecular mapping of QTLs conferring stay-green in grain sorghum (Sorghum bicolor L. Moench). Genome 43, 461-469.

Yadav, O.P. and Welzien, R.E. (1999) Breeding for adaptation to abiotic stresses. In: Khairawal, I.S., Rai, K.N., Andrews, D.J. and Harinarayana, G. (eds) Pearl Millet Breeding. Oxford and IBH Publishers, New Delhi, India, pp. 317-336.

Yadav, R.S., Hash, C.T., Bidinger, F.R., Cavan, G.P. and Howarth, C.J. (2002) Quantitative trait loci associated with traits determining grain and stover yield in pearl millet under terminal drought stress conditions. Theoretical and Applied Genetics 104, 67-83.

Yadav, R.S., Bidinger, F.R., Hash, C.T., Yadav, Y.P., Yadav, O.P., Bhatnagar, S.K. and Howarth, C.J. (2003) Mapping and characterization of QTL $\times \mathrm{E}$ interactions for traits determining grain and stover yield in pearl millet. Theoretical and Applied Genetics 106, 512-520.

Yadav, R.S., Hash, C.T., Bidinger, F.R., Devos, K.M. and Howarth, C.J. (2004) Genomic regions associated with grain yield and aspects of post-flowering drought tolerance in pearl millet across stress environments and tester background. Euphytica 136, 265-277.

Yau, S.K. (1997) Efficiency of alpha-lattice designs in international variety yield trials of barley and wheat. Journal of Agricultural Science 129, 5-9.

Zaidi, P.H., Rafique, S. and Singh, N.N. (2003a) Response of maize (Zea mays L.) genotypes to excess soil moisture stress: morpho-physiological effects and basis of tolerance. European Journal of Agronomy 19, 383-399.

Zaidi, P.H., Srinivasan, G. and Sanchez, C. (2003b) Morpho-physiological traits associated with variable field performance of different types of maize germplasm across multiple environments. Maydica 48, 207-220.

Zaidi, P.H., Srinivasan, G., Cordova, H.S. and Sanchez, C. (2004) Gains from improvement for mid-season drought tolerance in tropical maize (Zea mays L.). Field Crops Research 89, 135-152. 